\title{
LA UNIÓN EUROPEA Y EL PROCESO DE REVISIÓN CONSTITUCIONAL EN FRANCIA (1992-2008)
}

ANDONI PEREZ AYALA 
SUMARIO

I. LA INTEGRACIÓN EUROPEA Y SU INCIDENCIA CONSTITUCIONAL EN ESTADOS MIEMBROS DE LA UNIÓN EUROPEA. EN PARTICULAR, EN FRANCIA. II. EL TRATADO DE MAASTRICHT Y LA RECEPCIÓN DE LA UNIÓN EUROPEA EN LA CONSTITUCIÓN FRANCESA. III. LOS ACUERDOS DE SCHENGEN Y EL DERECHO DE ASILO EN EL NUEVO MARCO DE LA UNIÓN EUROPEA. IV. EL TRATADO DE ÁMSTERDAM, LA LIBRE CIRCULACIÓN DE PERSONAS Y EL CONTROL DE LAS CÁMARAS PARLAMENTARIAS. V. LA ORDEN DE DETENCIÓN EUROPEA Y LA COOPERACIÓN JUDICIAL EN LA UE. VI. EL FRUSTRADO PROYECTO DE TRATADO CONSTITUCIONAL DE LA UE. LA «CLÁUSULA TURCA». VII. EL TRATADO DE LISBOA Y LA REESCRITURA DEL TIT. XV RELATIVO A LA UE. EL REFORZAMIENTO DEL CONTROL PARLAMENTARIO. VIII. ÚLTIMAS MODIFICACIONES INTRODUCIDAS EN EL MARCO DE LA AMPLIA REVISIÓN CONSTITUCIONAL SOBRE LA MODERNIZACIÓN DE LAS INSTITUCIONES. 


\title{
LA UNIÓN EUROPEA Y EL PROCESO DE REVISIÓN CONSTITUCIONAL EN FRANCIA (1992-2008)
}

\author{
POR \\ ANDONI PEREZ AYALA \\ (Profesor Titular de Derecho Constitucional Comparado \\ en la Universidad del País Vasco / Euskal Herriko Unibertsitatea)
}

Si M. García-Pelayo hubiera vivido en el momento actual, es seguro que hubiese dedicado la atención debida a los Tratados de la Unión Europea que desde comienzos de la pasada década (1992, Maastricht) se han sucedido hasta el presente, cuando aún no ha concluido el proceso de ratificación del Tratado de Lisboa. Sin duda, el autor de Derecho Constitucional Comparado, ${ }^{1}$ obra que ha sido uno de los textos claves en la formación de varias generaciones de constitucionalistas a partir de la década de los sesenta del pasado siglo, se habría ocupado de estudiar a fondo las implicaciones constitucionales del proceso de integración europea; tanto por lo que se refiere al complejo y dificultoso proceso de constitucionalización de la Unión Europea en su conjunto como también por las implicaciones constitucionales que la integración europea, y en particular los Tratados de la UE, comportan para cada uno de los países miembros de la Unión.

Si bien hoy, cuando conmemoramos el centenario de M. García-Pelayo, no es posible, por ley de vida, que pueda seguir transmitiéndonos sus enseñanzas so-

${ }^{1}$ Una de las obras más leídas de la literatura constitucional en lengua española que hoy, tras más de medio siglo desde su publicación inicial en la década de los cincuenta, es una obra clásica de referencia y de obligada consulta, buena parte de la cual mantiene plena vigencia. Vid. la breve nota introductoria de M. Aragón para su última reedición (1984) en Alianza Universidad Textos. 
bre la materia, ello debe servirnos de estímulo para abordar el estudio de un tema como el que nos ocupa, que él hubiese tratado, sin duda, con más autoridad y que nosotros vamos a intentar desarrollar en estas líneas. En primer lugar, por el indudable interés que tiene para todos nosotros, ya que atañe a la definición de nuestro marco constitucional común como europeos. Y también por la novedad que supone el planteamiento de la cuestión constitucional en un marco nuevo, de ámbito supraestatal, como es la actual Unión Europea.

Todos los países miembros de la Unión Europea nos hemos visto afectados por el proceso de integración europea y, más concretamente, por los Tratados que a lo largo de ésta y la anterior décadas (1992-2008) han ido plasmando en términos jurídicos la evolución del proceso de integración. Pero quizá haya sido Francia uno de los países en los que la cuestión europea haya suscitado un debate más amplio, proyectándose sobre el conjunto de una ciudadanía que se ha movilizado y polarizado en torno a esta cuestión en mucha mayor medida que en otros países. Muestra ilustrativa de ello es el intenso proceso de revisiones constitucionales (nada menos que siete entre 1992 y 2008, lo que no ha ocurrido en ningún otro país) que ha tenido lugar en el país vecino y que pasamos a examinar a continuación.

\section{LA INTEGRACIÓN EUROPEA Y SU INCIDENCIA CONSTITUCIONAL EN LOS ESTADOS MIEMBROS DE LA UNIÓN EUROPEA. EN PARTICULAR, EN FRANCIA.}

1. El Tratado de la Unión Europea (TUE) suscrito en Maastricht $(1992)^{2}$ entre los doce Estados, entre ellos Francia, que en ese momento integraban las Comunidades Europeas, supone un punto de inflexión en el complejo proceso de integración europea que viene desarrollándose desde la década de los cincuenta. A este Tratado inicial, por el que se instituía la Unión Europea, le sucederán sendos Tratados de reforma de aquél —Amsterdam (1997), Niza (2001), el frustrado proyecto de Tratado constitucional de Roma (2004) y Lisboa (2007), pendiente de ratificación en el momento actual- que, conjuntamente, van a ir configurando, no sin contradicciones e incluso con retrocesos en algunos casos, el peculiar marco institucional de una Unión Europea en progresiva expansión. Así lo corroboran las sucesivas ampliaciones de la UE

2 Su firma tuvo lugar en esta ciudad holandesa el 7 de Febrero de 1992, si bien no entró en vigor hasta el 1 de Noviembre de 1993, tras la ratificación de los doce Estados que, en ese momento, integraban la inicial Unión Europea. 
en este último periodo, hasta llegar a los veintisiete países actuales; a los que habría que añadir las peticiones de adhesión en curso de tramitación en el momento presente. ${ }^{3}$

Los referidos Tratados (de la UE), además de las repercusiones que han tenido en el proceso de integración europea, van a tener también una importante incidencia en los Estados integrantes de la UE; en particular, en un terreno específico (que es el que a nosotros más nos interesa y que será el objeto de estas líneas) como es el constitucional; y más concretamente, en lo que concierne a los cambios constitucionales derivados de los referidos Tratados. A este respecto, es preciso constatar, antes de seguir adelante, que a diferencia de los Tratados precedentes sobre las Comunidades Europeas, que apenas habían tenido repercusiones constitucionales en los Estados integrantes de éstas, los Tratados suscritos a partir de Maastricht (1992) van a tener una muy apreciable incidencia constitucional en los países miembros de la Unión Europea.

Se trata de una tendencia que afecta, de forma generalizada, a buena parte de los países participantes en el proceso de integración europea. Tal es el caso, por reseñar sólo los países limítrofes, además de Francia, de Alemania, que va a realizar varias reformas constitucionales con el fin de adaptar la Ley Fundamental de Bonn al nuevo marco establecido por el Tratado de la UE. ${ }^{4}$ Bélgica, por su parte, en el marco de la refundación constitucional que efectúa durante 19931994, se planteará la cuestión de la compatibilidad de sus normas constitucionales con el Tratado de la UE. ${ }^{5}$ Portugal realizará, así mismo, una nueva reforma constitucional, tras las dos grandes revisiones anteriores de 1982 y 1989 rectificando profundamente el modelo original de la revolución de los claveles, para constitucionalizar explícitamente su incorporación al proceso de integración europea. ${ }^{6}$ Tan sólo Italia, entre los países de nuestro entorno más próximo, no

3 Además de los países integrantes de la antigua Yugoslavia, que han mostrado su intención de adherirse a la UE, Turquía, que plantea problemas específicos, como se examinará más adelante; $y$, muy recientemente, también Islandia, que había mantenido hasta ahora una posición distante ante la UE.

${ }^{4}$ Ley de 21 de diciembre de 1992, de reforma de la Ley Fundamental. Así mismo, Sentencia del Tribunal Constitucional Federal de 12 de Octubre de 1993, sobre la ley de ratificación del Tratado de la UE. Ambas pueden verse, en lengua española, en Boletín de Legislación Extranjera (BLE) de las Cortes Generales, no 147-148, 1994, pags. 31, 35 y ss.

5 Dictamen del Consejo de Estado, de 6 de Mayo de 1992, sobre la compatibilidad entre el Tratado de la UE y la Constitución; vid. (también, en lengua española), BLE, no 147-148, 1994, pag. 73 y ss.

${ }^{6}$ Ley Constitucional no 1/1992, de 25 de Noviembre; vid. BLE, no 147-148, pag. 131. Un breve comentario sobre esta revisión constitucional puede verse en mi trabajo «Tres décadas de evolución constitucional en Portugal (1976-2006)»; en particular, el apartado sobre «La revisión 
efectuó revisión constitucional alguna con motivo del TUE, si bien no faltaron voces autorizadas que se pronunciaron a favor de la misma. ${ }^{7}$

También en España se han dejado sentir los efectos constitucionales de los Tratados de la UE; aunque, en nuestro caso, la labor realizada en el terreno de la adecuación constitucional al cambiante marco de la UE haya sido muy escasa. En cualquier caso, la única reforma constitucional (tema tabú entre nosotros por otras razones, que nada tienen que ver con la UE) realizada hasta ahora, ha venido originada precisamente por el inicial Tratado de la UE de Maastricht (1992). ${ }^{8}$ Y en el momento actual, desde la pasada legislatura, una de las cuestiones que está planteada como objeto de una próxima, aunque incierta, reforma constitucional es la introducción de una referencia expresa en el texto constitucional a nuestras relaciones con la Unión Europea. ${ }^{?}$

2. En este marco general, caracterizado por la incidencia constitucional en los Estados miembros de los Tratados de la UE, Francia va a ocupar un lugar muy destacado ya que ha sido este país uno de los que ha experimentado más cambios constitucionales como consecuencia de los sucesivos Tratados de la UE. Dada la atención que esta cuestión ha despertado en los medios constitucionales del país vecino y la controversia doctrinal suscitada en torno al tema, tiene especial interés examinar la evolución del proceso seguido a este respecto desde comienzos de la pasada década; así como el contenido de los sucesivos cambios introducidos por el legislador constitucional francés, quien se ha mostrado particularmente activo en este terreno.

La Constitución de la $\mathrm{V}$ República no contenía, en su redacción originaria de 1958, ninguna disposición relativa al proceso de integración europea ni al lugar de la República francesa en la Europa integrada. Ello es lógico ya que es precisamente en ese mismo año (1958), coincidiendo con el nacimiento de la V República, cuando se inicia el proceso de integración comunitaria europea con la creación de la Comunidad Económica Europea $(\mathrm{CEE}) ;{ }^{10}$ proceso que tendrá un

de 1992. La constitucionalización de la inserción de Portugal en la UE», Revista de Derecho Político, no 70, 2007, pag. 123 y ss.

7 Vid. M. LUCIANI: «La Constitution italienne et les obstacles a l'integration européenne», Revue Française de Droit Constitutionnel, no 12, 1992, pag. 663 y ss.

${ }^{8}$ Reforma constitucional de 27 de Agosto de 1992 (BOE de 28 de Agosto), de conformidad con la Declaración del Tribunal Constitucional de 1 de Julio de 1992.

9 Informe del Consejo de Estado sobre modificaciones de la Constitución española, 2006, 361 pags; en particular, el Apartado III: «La recepción en la Constitución del proceso de construcción europea», pags. 41-127

${ }_{10}$ El Tratado Constitutivo de la Comunidad Económica Europea (CEE), firmado en Roma el 25 de Marzo de 1957, entró en vigor el 1 de Enero de 1958, unos meses antes que la Constitución de la V República (4 de octubre de 1958). 
desarrollo continuado durante las siguientes décadas hasta llegar al punto de inflexión del Tratado de Maastricht (1992) que da lugar al nacimiento de la Unión Europea. No cabe, por tanto, achacar al constituyente francés de 1958 falta de previsión por no hacer referencia a una situación que entonces no existía y que tardará varias décadas en hacerse realidad.

Tampoco en las casi tres décadas y media que transcurren entre 1958, fecha en la que coinciden el nacimiento de la V República y el inicio del proceso de integración comunitaria europea, y 1992, fecha en la que coinciden el nacimiento de la UE y el inicio del proceso continuado de revisión constitucional en Francia que se prolonga hasta la actualidad, se introdujo ninguna disposición constitucional que hiciese referencia a la posición de la República francesa en relación con la Europa comunitaria. Hay que reseñar que esa falta de plasmación constitucional del proceso de integración comunitario era común al resto de los países europeos, que durante este periodo no introducen modificaciones en sus respectivos textos constitucionales por este motivo. En Francia, en particular, las cinco revisiones constitucionales llevadas a cabo en este periodo (19581992) van a girar en torno a problemas domésticos, ${ }^{11}$ eludiendo cualquier referencia a la integración europea en curso.

A falta de disposiciones constitucionales referidas específicamente a la integración comunitaria europea y al lugar de la República francesa en ese nuevo marco, serán las disposiciones relativas a los Tratados y Acuerdos Internacionales del Tit. VI (arts. 52-55), las que proporcionen cobertura constitucional a los Tratados comunitarios suscritos por las autoridades francesas desde el Tratado de Roma (1957), que dará lugar al nacimiento de las Comunidades Europeas (CCEE), hasta el de la Unión Europea con el Tratado de Maastricht (1992). A partir de este momento, sin embargo, la máxima autoridad en materia de interpretación de la Constitución, el Consejo Constitucional, estima que la cobertura constitucional que proporcionan las referidas disposiciones sobre los Tratados y Acuerdos Internacionales, con carácter general, es insuficiente para dar cuenta de la nueva realidad que supone la Unión Europea y los Tratados que la instituyen. Se hace necesario, en consecuencia, realizar la revisión constitucional para que estos puedan tener el adecuado encaje constitucional.

${ }^{11}$ Revisiones constitucionales de 4 de Junio de 1960, modificando los arts. 85 y 86 del Tit. XII de la Constitución (derogado por la posterior revisión constitucional de 1995), relativo a la Comunidad francesa; de 6 de Noviembre de 1962, sobre elección del Presidente de la República por sufragio universal directo (arts. 6 y 7); de 30 de Diciembre de 1963, sobre la duración de las sesiones de las Cámaras parlamentarias (art. 28); de 29 de Octubre de 1974, sobre la intervención de los parlamentarios en el control de constitucionalidad de las leyes (art. 61); y de 28 de Junio de 1976, sobre impedimento o fallecimiento de un candidato a la elección presidencial (art. 7). 
De acuerdo con esta posición del Consejo Constitucional, el legislador constitucional francés introduce un nuevo Título (inicialmente integrado por cuatro artículos adicionales: $88-1$ a $88-4$, a los que nos referiremos más ampliamente a continuación) dedicado específicamente a las Comunidades Europeas y la Unión Europea. De esta forma tenía acogida, por primera vez, en el texto constitucional francés, al igual que ocurrirá en los textos constitucionales de otros países europeos ${ }^{12}$ el proceso de integración europea. A esta primera incursión del constitucionalismo nacional en el espacio político que va delimitando progresivamente la UE, le sucederán posteriormente, tanto en Francia como en otros países de la UE, una serie de revisiones constitucionales que irán configurando progresivamente la nueva dimensión europea del constitucionalismo de los países miembros de la UE.

En Francia, en particular, nada menos que siete revisiones constitucionales tendrán lugar a partir de entonces (en 1992, 1993, 1999, 2003, 2005 y dos en 2008) con la finalidad de ir adaptando el marco constitucional a la progresiva evolución de la Unión Europea. ${ }^{13}$ Esta atención continuada que el legislador constitucional francés ha venido prestando a la "cuestión europea» desde los comienzos de la pasada década hasta la actualidad da cuenta de la importante relevancia que para él tiene como elemento estructural, y no meramente coyuntural, del sistema constitucional francés. Una relevancia que no es previsible que vaya a menguar sino, más bien, todo lo contrario, en un próximo futuro, en el que el proceso de integración europea va a seguir desarrollándose y, en consecuencia, va a seguir requiriendo nuevas adaptaciones constitucionales en los Estados miembros.

Hay un último aspecto al que es preciso hacer una breve referencia, como es el lugar que ocupan las revisiones constitucionales efectuadas como consecuencia de la integración europea, a lo que vamos a ceñirnos en estas líneas, en el

12 El Boletín de Legislación Extranjera (BLE) de las Cortes Generales ha dedicado un $\mathrm{n}^{\mathrm{o}}$ monográfico $(147-148,1994)$ a las repercusiones constitucionales del Tratado de la Unión Europea de Maastricht en los Estados miembros, acompañado de un estudio introductorio de Pablo PÉREZ TREMPS, sobre «el ordenamiento comunitario y el estatal: las condiciones constitucionales al proceso de ratificación del Tratado de Maastricht en el Derecho comparado", pags. 7-30

13 Estos continuos cambios constitucionales en el país vecino han venido siendo comentados, entre nosotros, por A.J. SÁNCHEZ NAVARRO en Teoría y Realidad Constitucional (TRC), a partir del no 3 (primer semestre de 1999) hasta el momento presente (no 22, segundo semestre de 2008) en la sección "Panorámica sobre otros sistemas constitucionales" que, con periodicidad aproximadamente anual, ofrece esta publicación sobre la actualidad constitucional en otros países; en particular, en Francia, a cargo del referido autor, cuyos comentarios sobre la actualidad constitucional francesa son de la máxima utilidad para conocer la reciente evolución constitucional del país vecino. 
conjunto del amplio proceso de revisión constitucional emprendido en la V República desde comienzos de la pasada década. A este respecto, hay que reseñar que es precisamente la primera revisión constitucional efectuada con motivo del Tratado de la UE de Maastricht (1992) la que abre el intenso y continuado proceso que, a través de nada menos que de diecinueve revisiones constitucionales entre 1992 y $2008,{ }^{14}$ se prolonga hasta el momento presente (comienzos de 2009). Y que, previsiblemente, va a continuar en los próximos años. Se trata, sin duda, de una de las experiencias de cambio constitucional de mayor amplitud, en cuyo marco hay que situar las sucesivas revisiones constitucionales relativas a la UE, que pasamos a examinar a continuación.

\section{EL TRATADO DE MAASTRICHT Y LA RECEPCIÓN DE LA UNION EUROPEA EN LA CONSTITUCIÓN FRANCESA}

1. La firma del Tratado de la Unión Europea, en Maastricht (1992), es el hecho que da lugar, como ya se ha indicado anteriormente, a la revisión constitucional de 1992; la sexta de las revisiones ${ }^{15}$ de la Constitución de la V República desde su nacimiento en 1958 y, al mismo tiempo, la primera de las que van a sucederse en el intenso y continuado proceso de revisión constitucional que se está desarrollado en Francia desde los comienzos de la pasada década. Con ella Francia, al igual que otros países de la UE pero quizá con mayor insistencia como lo muestran las siete revisiones que se han realizado sobre este mismo tema a partir de entonces, iniciaba un proceso de adaptación constitucional al nuevo marco de la UE que, en el momento actual, sigue abierto y que probablemente tendrá continuación con nuevas revisiones constitucionales

El origen de esta primera revisión de 1992 radica en una Decisión del Consejo Constitucional, ${ }^{16}$ instado por Presidente de la República (F. Mitterrand) para que se pronunciase sobre la compatibilidad del Tratado de la UE de Maastricht con la Constitución francesa. Este requerimiento a la más alta autoridad constitucional sobre la cuestión que se planteaba está contemplado expresamente en

${ }^{14}$ La Documentation Française, en su colección «Documents d'Etudes» ha dedicado un cuaderno monográfico ${ }^{\circ} 1.20$ (elaborado por Christian BIGAUT) a Les revisions de la Constitution de 1958, que resulta muy útil (y que hemos utilizado en la realización de este trabajo) para conocer las fuentes documentales de las revisiones constitucionales francesas.

15 Ley Constitucional no 92-554, de 25 de Junio de 1992 (J.O. de 26 de Junio) por la que se añade a la Constitución un nuevo Título: «De las Comunidades Europeas y de la Unión Europea»

${ }_{16}$ Decisión no 92-308 DC de 9 de Abril, (J. O. De 11 de Abril) declarando contrarias a la Constitución tres disposiciones del Tratado de la Unión Europea 
el art. 54 (modificado precisamente en esta revisión en los términos que se expondrá a continuación; ver infra). En su pronunciamiento, el Consejo Constitucional estima que el Tratado de la UE de Maastricht sólo puede ser suscrito por la República francesa a condición de que previamente se introduzcan una serie de modificaciones en el texto constitucional.

Tres eran, a juicio del Consejo Constitucional, los puntos en los que el Tratado de la UE de Maastricht colisionaba con la Constitución francesa. En primer lugar, la previsión de que los ciudadanos de otros países de la UE pudieran ocupar en Francia cargos municipales (art. 8.B.1 del TCE), lo que entra en contradicción con el principio de soberanía nacional, recogido en el art. 3 de la Constitución. Así mismo, la previsión contenida en el Tratado sobre el establecimiento de una política monetaria única, gestionada por el Banco Central Europeo (BCE) (art. 105 y ss. TCE) que, a juicio del Consejo Constitucional, entra también en contradicción con el principio de soberanía nacional. Y finalmente, la política común de visados (art. 61 y ss. TCE) que colisionaba, al igual que las dos anteriores, con las condiciones esenciales para el ejercicio de la soberanía. ${ }^{17}$

De acuerdo con este pronunciamiento del Consejo Constitucional (CC), el entonces Presidente de la República, F. Mitterrand, ejerció la iniciativa para la revisión constitucional, en los términos previstos en el art. 89. Tras la obtención del voto favorable en las dos Cámaras, en términos idénticos, tal y como exige la referida disposición sobre la revisión constitucional, fue sometida al Parlamento reunido en Congreso, donde fue aprobada definitivamente por una amplia mayoría. Esta amplia mayoría parlamentaria contrasta fuertemente, sin embargo, con el muy apretado resultado del referéndum convocado al efecto, en el que la diferencia entre los votos favorables y contrarios fue mínima. ${ }^{18}$

2. En síntesis, esta primera revisión constitucional, originada por el Tratado de Maastricht (1992), introducía un nuevo Título (inicialmente, el XIV; actualmente, el XV): De las Comunidades Europeas y de la Unión Europea, dedicado específicamente a constitucionalizar de forma expresa la inserción de la República francesa en la Unión Europea que nacía en ese momento, precisamente como consecuencia del referido Tratado. Es preciso llamar la atención sobre la

17 Vid. J.C. ESCARRAS: «Il Trattato di Maastricht e la Costituzione francese», Quaderni Costituzionzli, no 2, 1993, pags. 345 y ss.; así mismo, F. LUCHAIRE: «L'Union Européenne el la Constitution: la Décision du Conseil Constitutionnel», Revue de Droit Public et Science Politique, no 3, 1992, pags. 589 y ss.

18 En el referéndum celebrado el 20 de Septiembre de 1992 la abstención fue del 30,3\%; los votos favorables alcanzaron el $51,05 \%$, frente al $48,95 \%$ de votos contrarios; resultados no esperados que constituyeron una sorpresa (que volverá a repetirse en 2005, con motivo del referéndum sobre el Tratado constitucional). 
ubicación de este nuevo Título en el texto constitucional, separadamente y diferenciado claramente del relativo a los Tratados y Acuerdos Internacionales (Tit. VI), que hasta ese momento había proporcionado cobertura constitucional a los propios Tratados comunitarios. Ello pone de relieve la especificidad y el carácter diferenciado que, en relación con el resto de los Tratados y Acuerdos internacionales, el propio legislador constitucional francés otorga a los Tratados relativos al proceso de integración europea.

Inicialmente, el proyecto de ley constitucional presentado por el Gobierno para dar cumplimiento a la Decisión del Consejo Constitucional se limitaba a introducir dos artículos adicionales nuevos. En el primero de ellos se preveía que Francia, en cumplimiento del Tratado de Maastricht, otorgaba su consentimiento «bajo reserva de reciprocidad» a la transferencia de competencias necesarias para el establecimiento de la Unión Económica y Monetaria (UEM) europea, así como para fijar las normas relativas al cruce de fronteras entre los Estados miembros de la Europa comunitaria. En el segundo, de acuerdo también con las indicaciones del Consejo Constitucional, se refería a las condiciones del ejercicio del derecho de sufragio en las elecciones municipales por ciudadanos de la Unión Europea residentes en Francia.

Estas dos únicas disposiciones iniciales del proyecto de ley constitucional se verán ampliadas, en el curso de la tramitación parlamentaria de la revisión con arreglo al art. 89, con otras dos nuevas disposiciones adicionales más, a agregar a las anteriores. En la primera de ellas se constitucionalizaba expresamente la participación de Francia en las Comunidades Europeas (CCEE) y en la Unión Europea (UE); en la otra, se preveía la intervención preceptiva del Gobierno y las Cámaras en los actos comunitarios que comporten disposiciones de naturaleza legislativa. Así mismo, en el curso de la tramitación parlamentaria se introdujeron también una serie de disposiciones, no previstas inicialmente y que nada tenían que ver con el hecho que originaba esta revisión, tales como la constitucionalización de la lengua francesa (art. 2) ${ }^{19}$ o el estatuto de los territorios de ultramar (art. 74) (de lo que no nos vamos a ocupar en estas líneas por caer fuera del tema que constituye el objeto de este trabajo). Una mención especial merece la revisión del art. 54, de la que sí nos ocuparemos más adelante (ver infra) ya que, aunque ubicada fuera del Título relativo a la UE, sí guarda relación, como se verá en su momento, con el proceso de inserción de Francia en el nuevo marco de la Unión Europea.

${ }^{19}$ Sobre la revisión constitucional en este tema, vid. R. DEBRASCH: «La reconnaissance constitutionnelle de la langue française», Revue Française de Droit Constitutionnel (RFDC), $\mathrm{n}^{\circ} 11$, 1992, pag. 457 y ss. 
En la redacción definitivamente aprobada por el legislador constitucional francés de 1992, el nuevo Título (XV) introducido está dedicado específicamente a "Las Comunidades Europeas y la Unión Europea». ${ }^{20}$ Esta doble alusión, a las Comunidades y a la Unión europeas, fue introducida en el curso del debate parlamentario en las Cámaras ya que en el proyecto inicial tan sólo había una referencia a la Unión (sin mención alguna a las Comunidades). No está de más la referencia explícita a ambas - Comunidades y Unión europeas - tal y como se hace en el texto finalmente aprobado ya que debido a la peculiaridad de la construcción europea, que distingue entre ambas entidades, con estructura y funciones no coincidentes, es aconsejable la referencia expresa a ambas para evitar los riesgos de posibles confusiones.

3. La primera de las disposiciones (art. 88.1) del referido nuevo Título tiene como finalidad dar relieve constitucional de forma expresa a la participación de Francia en las Comunidades y la Unión europeas. Como se acaba de indicar no estaba prevista en el proyecto inicial y fue introducida en el curso de la tramitación parlamentaria de la revisión en las Cámaras. De esta forma, la República francesa quedaba anclada constitucionalmente en el proceso de integración europea en los términos fijados por los Tratados -comunitarios y de la Unión- a los que se hace referencia en esta nueva disposición constitucional (art. 88.1). Cabría preguntarse, como han señalado algunos comentarios, si la referencia que en ella se hace al «ejercicio en común» de las competencias estatales es la expresión más correcta para referirse a la integración europea ya que ésta supone, con arreglo a los propios Tratados, una verdadera transferencia de competencias a la Unión o a la Comunidad europeas, más que un ejercicio en común de competencias estatales propias. ${ }^{21}$

La colisión que, de acuerdo con la reseñada Decisión del Consejo Constitucional, se daba entre el principio constitucional de soberanía nacional (art. 3) y las previsiones del Tratado de la Unión Europea sobre el establecimiento de una política monetaria única en la UE así como de una política común de visados, obligaba a introducir modificaciones constitucionales que salvasen estos obstáculos. A ello responde la inserción del nuevo art. 88-2 que prevé, bajo reserva de reciprocidad y de acuerdo con las modalidades previstas en el Tratado de la UE, el consentimiento de Francia a «la transferencia de las competencias necesarias

${ }^{20}$ Un comentario sobre el conjunto de la ley constitucional puede verse en F. LUCHAIRE: "L'Union Européenne el la Constitution. Comentaire de la Loi Constitutionnel du 25 juin 1992", Revue de Droit Public et Science Politique, no 4, 1992, pag. 956 y ss.

${ }^{21}$ P. PÉREZ TREMPS, en su comentario introductorio sobre «el ordenamiento comunitario y el estatal ...», op. cit., pag. 17. 
para el establecimiento de la unión económica y monetaria europea»; transferencia que es extensible, bajo las mismas condiciones de reserva de reciprocidad y de conformidad con el TUE, a las competencias necesarias para «la determinación de las normas relativas al cruce de fronteras exteriores de los Estados miembros de la Comunidad europea».

Si bien la finalidad de esta nueva disposición (art. 88-2) no era otra que la de proporcionar cobertura constitucional a las transferencias competenciales, en las materias señaladas, a favor de la UE, la forma en que se hace puede ser también objeto de algunas observaciones críticas. Así, la alusión a la reserva de reciprocidad, cláusula usual en el derecho internacional, puede resultar problemática en el marco específico de la UE ya que puede inducir a una interpretación que excluya a algunos países, miembros de la Unión y de las Comunidades europeas, que tienen un régimen especial tanto en materia económica y monetaria como fronteriza. Así mismo, la alusión explícita que se hace en la disposición que comentamos al "Tratado de la UE de 7 de febrero de 1992» puede dar lugar a una rigidificación excesiva, e innecesaria, que obligue a realizar una nueva reforma constitucional cada vez que se cambie el Tratado. ${ }^{22}$

El nuevo art. 88-3, inducido también, como el anterior, por la misma Decisión del Consejo Constitucional, proporciona, por su parte, cobertura constitucional a la aplicación del derecho de sufragio en las elecciones municipales para los ciudadanos de la Unión Europea; lo que no sólo afectaba a Francia sino a todos los países de la $\mathrm{UE}^{23}$. Hay que puntualizar, no obstante, que en el caso de Francia, a diferencia de otros países de la UE, el derecho de sufragio pasivo queda restringido, excluyendo expresamente a los Alcaldes y adjuntos (Tenientes de Alcalde); así como también se excluye la participación de los ciudadanos no franceses de la UE en la designación de los electores senatoriales o en la elección de senadores. Ello es debido al particular sistema francés de elección de senadores, en el que, a diferencia de otros países europeos, participan los cargos municipales reseñados. Se trata de una "excepción francesa» en el régimen electoral municipal, si bien contemplada en el propio Tratado de Maastricht, que prevé expresamente la posibilidad de «establecer excepciones [al derecho de sufragio pasivo, en este caso] cuando así lo justifiquen problemas específicos de un Estado miembro» (art. 8.B.1 TCE).

${ }^{22}$ Riesgo que ha sido advertido por varios comentaristas; entre otros, por P. PÉREZ TREMPS en el referido comentario introductoria, op. cit., pag. 17.

${ }^{23}$ Incluida España, que se ve obligada a realizar la única reforma constitucional llevada a cabo hasta ahora: modificación del art. 13.2 y, así mismo, en relación con esta modificación constitucional sobre el derecho de sufragio pasivo, del art. 177 de la Ley Orgánica del Régimen Electoral General (LOREG). 
Por último, el art. 88-4, con el que se completa el grupo de disposiciones constitucionales que integran el nuevo Tit. (XV) dedicado a la Unión y las Comunidades europeas, tiene como finalidad garantizar constitucionalmente la intervención de las Cámaras parlamentarias francesas en «los actos comunitarios que comportan normas de naturaleza legislativa», cuyas propuestas deberán ser presentadas por el Gobierno ante la Asamblea Nacional y el Senado, en cuanto éstas hayan sido transmitidas al Consejo de las Comunidades. Se pretendía con ello asegurar la participación de la máxima instancia representativa francesa - las Cámaras parlamentarias - en el proceso de decisión comunitario; en particular, en las normas de carácter legislativo. Esta previsión, que no figuraba en el proyecto inicial de ley constitucional, fue introducida (al igual que el nuevo art. 88.1 ya reseñado, ver supra) en el curso de la tramitación parlamentaria en las Cámaras de esta revisión. ${ }^{24}$

Las cuatro nuevas disposiciones constitucionales (arts. 88-1, 88-2, 88-3 y 884) comentadas en los párrafos precedentes, agrupadas en el, así mismo, nuevo Título (XV) dedicado específicamente a las Comunidades Europeas y la Unión Europea, establecen conjuntamente el nuevo marco constitucional relativo a los referidos ámbitos europeos. Ello suponía una importante novedad en el esquema constitucional de la V República, al insertar en él por primera vez, de forma expresa, la dimensión europea, no contemplada hasta ese momento; al igual que ocurría en otros países europeos, que también empezarán, a partir del Tratado de la UE de Maastricht (1992), a incluir en sus textos constitucionales la referencia europea. ${ }^{25}$ Por otra parte, y de cara al futuro, esta primera revisión constitucional «europea» va a ser el punto de partida de un proceso de progresiva adecuación constitucional de la $\mathrm{V}$ República al cambiante marco europeo que, a través de sucesivas revisiones (seis más, que se examinarán a continuación), se prolonga hasta el momento actual.

En este sentido, es preciso advertir que este marco constitucional europeo inicial, en los términos establecidos por la revisión de 1992, ha ido experimentando cambios, en algunos casos importantes, al compás de las sucesivas refor-

${ }^{24}$ Ello ha dado lugar a la reforma de los reglamentos de las Cámaras, que en Francia han de pasar obligadamente el filtro del Consejo Constitucional (Decisiones 92-314 y 92-315). Un comentario al respecto puede verse en F. LUCHAIRE: «L'Union Europaenne et la Constitution. Les Reglèments des Assemblées Parlamentaires», Revue de Droit Public et Science Politique, no 2, 1993, pag. 301 y ss.

${ }_{25}^{25}$ Las modificaciones introducidas en los textos constitucionales, así como la posición de los altos órganos consultivos o jurisdiccionales de los distintos países europeos, pude verse en el $\mathrm{n}^{\mathrm{o}}$ monográfico 147-148, 1994 del Boletín de Legislación Extrajera (BLE) de las Cortes Generales, dedicado al «Tratado de la Unión Europea (Tratado de Maastricht). Consecuencias constitucionales». 
mas de los Tratados europeos (Ámsterdam, Niza, Roma y el frustrado proyecto de Tratado constitucional, Lisboa, aun pendiente de completar la ratificación). Ello ha dado lugar a repetidas modificaciones, que se examinarán a continuación, del texto constitucional resultante de esta primera revisión de 1992, bien mediante rectificación de las disposiciones introducidas en ésta o bien mediante adición de otras nuevas (arts. 88.5, 88.6, 88.7). En cualquier caso, puede afirmarse que esta «revisión de la revisión» resultante de las sucesivas reformas de los Tratados europeos no ha quebrado la continuidad, al menos en sus aspectos esenciales, del esquema básico originario de 1992.

4. Si bien las nuevas disposiciones constitucionales comentadas en los párrafos precedentes eran el elemento central de la revisión constitucional de 1992, ésta afectó también a otras tres (arts. 2, 54 y 74) ubicadas fuera del nuevo Título (XV) relativo a la Unión y las Comunidades europeas. Dos de ellas (arts 2 y 74) no tenían nada que ver con la adecuación constitucional de Francia al nuevo marco de la UE, refiriendose la primera de ellas a la constitucionalización de la lengua francesa (art. 2) y la otra al status de los territorios de ultramar (art. 74).; en ambos casos se aprovechó el proceso de revisión constitucional en marcha originado por el Tratado de la Unión Europea para ampliar la revisión a las referidas disposiciones, a las que no había alusión alguna en el proyecto inicial de ley constitucional. Nos limitaremos a reseñarlas, sin detenernos en su examen, ya que por su contenido, ajeno por completo a las repercusiones constitucionales de la integración europea, caen fuera del objeto de nuestro trabajo.

La otra disposición constitucional (art. 54) afectada por la revisión sí merece un comentario ya que, aunque no forme parte del nuevo Título (XV) relativo a la UE, sí tiene, sin embargo, una estrecha relación con el tema que nos ocupa. Su ubicación en el Título VI, relativo a "los Tratados y Acuerdos Internacionales», que proporciona el marco constitucional que permite suscribir el Tratado de la UE, la conecta directamente con éste; como, por otra parte, se corrobora en la propia exposición de motivos del proyecto de ley constitucional. ${ }^{26}$ Pero, además, la propia revisión de esta disposición constitucional, en los términos que a continuación se señalarán, dará paso a la utilización de las nuevas posibilidades que abre (a los miembros de las Cámaras) para poder cuestionar la misma constitucionalidad de los Tratados europeos.

${ }^{26}$ El texto integro de la exposición de motivos del proyecto de ley constitucional, que permite conocer la posición mantenida por el legislador constitucional ante el Tratado de Maastricht, puede verse en Les revisions de la Constitution de 1958, La Documentation Française, Paris, 2007, pags. 19-20. 
En su redacción originaria, no modificada desde 1958, el art. 54 preveía la intervención del Consejo Constitucional ${ }^{27}$ para que verificase si un compromiso internacional contiene alguna cláusula contraria a la Constitución; en cuyo caso, sólo podría ratificarse después de su reforma, como había ocurrido con el propio Tratado de la UE. La intervención del Consejo Constitucional sólo podía producirse, de acuerdo con el texto vigente hasta esta revisión, a requerimiento del Presidente de la República, del Primer Ministro o de los Presidentes de la Asamblea Nacional o del Senado. Pues bien, la revisión que comentamos (1992) amplía el elenco de sujetos legitimados para requerir la intervención del Consejo Constitucional, abriendo la posibilidad de que también puedan hacerlo sesenta diputados o igual número de senadores.

Se trata de una revisión que se inscribe en una orientación similar a la efectuada casi dos décadas antes (1974), por iniciativa del entonces Presidente V. Giscard d'Estaign, modificando el art. 61 de la Constitución ${ }^{28}$ para hacer posible que también el mismo número (60) de diputados o senadores (además del Presidente de la República, del Primer Ministro o de los Presidentes de las Cámaras) pudiesen plantear ante el Consejo Constitucional la constitucionalidad de una norma legislativa, antes de su promulgación. Parece obvio que no tenía mucho sentido, una vez admitido que un determinado número de diputados o de senadores pudiese plantear ante el Consejo Constitucional la constitucionalidad de una ley, negar esa misma posibilidad con motivo de un Tratado Internacional.

Las nuevas posibilidades que abría el art. 54 revisado tuvieron materialización inmediata a través de la impugnación ante el Consejo Constitucional por un grupo de parlamentarios de la constitucionalidad del propio Tratado de la UE que se acababa de firmar en Maastricht. En su respuesta, ${ }^{29} \mathrm{el} \mathrm{Consejo} \mathrm{cons-}$ titucional confirma, sin embargo, la compatibilidad del referido Tratado con la Constitución francesa, gracias precisamente a la revisión constitucional efectuada, sin que pueda apreciarse ninguna extralimitación del legislador constitucional ni en cuanto a los límites materiales, al no existir vulneración de cláusula de intangibilidad alguna, ni tampoco de los límites formales. Quedaba así

${ }^{27}$ Sobre el papel del Consejo Constitucional como «actor» de la revisión, vid. S. PIERRECAPS: «Les révisions de la Constitution de la Cinquième République: temps, conflicts, stratégies», Revue de Droit Public et Science Politique, no 2, 1998, pag. 422 y ss.

${ }^{28}$ Ley Constitucional no 74-904 de 29 de Octubre de 1974 (J.O. de 30 de Octubre), modificando el art. 61 de la Constitución

29 Decisión 93-312, de 2 de Septiembre de 1992 (J.O. de 3 de Septiembre); vid. L. FAVOREU y P. GAIA: «Les décisions du Conseil Constitutionnel relatives au Traité sur L’Union européenne», Revue Française de Droit Constitutionnel, no 11, 1992, pag. 389 y ss. 
sancionada, por la más alta autoridad en materia de interpretación de la Constitución, la recepción constitucional de la Unión Europea, que tendrá continuidad en las sucesivas revisiones constitucionales que examinamos a continuación.

\section{LOS ACUERDOS DE SCHENGEN Y EL DERECHO DE ASILO EN EL NUEVO MARCO DE LA UNIÓN EUROPEA}

La regulación del derecho de asilo en el marco del proceso de integración europea, y particularmente en el ámbito de la progresiva conformación de un espacio judicial común, es el objeto de una nueva revisión constitucional poco más de un año después (1993); ${ }^{30}$ en este caso, con la particularidad de ser la última de las realizadas bajo el mandato presidencial de F. Mitterrand. Aunque las disposiciones afectadas por esta revisión constitucional no entran dentro del Tit. (XV) dedicado específicamente a la Unión Europea (como también ocurría con alguna de las disposiciones (art. 54) afectadas por anterior revisión de 1992), es preciso tratar sobre el tema aquí ya que la revisión constitucional llevada a cabo se inscribe plenamente en la senda de integración europea marcada en Maastricht; ${ }^{31} \mathrm{o}$, para ser más exactos, tiene relación directa con las implicaciones constitucionales que en los Estados miembros se derivan del proceso de integración europea.

El origen de esta nueva revisión constitucional radica en los Acuerdos de Schengen, ${ }^{32}$ en virtud de los cuales un grupo de países miembros de las entonces Comunidades Europeas (CC.EE.), entre ellos Francia, acuerdan establecer una regulación común en materia de controles fronterizos, lo que va a tener repercusiones constitucionales sobre el derecho de asilo. A este respecto, va a ser decisivo el pronunciamiento del Consejo Constitucional estimando que algunas disposiciones de la normativa adoptada para la aplicación en Francia de los Acuerdos de Schengen comportaban una limitación inconstitucional del derecho

${ }^{30}$ Ley Constitucional no 93-1256, de 25 de Noviembre de 1993 (J.O. de 26 de Noviembre), relativa a los Acuerdos internacionales en materia de derecho de asilo.

31 Vid. Georges VEDEL: «Schengen et Maastricht», Revue Française de Droit Administratif (RFDA), no 8, 1992, pag. 179.

32 Acuerdos firmados en esta localidad el 14 de Junio de 1985 y el 19 de Junio de 1990, inicialmente suscritos por cinco países: Alemania, Francia, Países Bajos, Bélgica y Luxemburgo, a los que posteriormente se fueron sumando otros países europeos. El denominado Acervo Schengen fue incorporado como protocolo anexo al Tratado de la Union Europea por el Tratado de Amsterdam (1997). 
de asilo, ${ }^{33}$ en los términos en que éste es reconocido constitucionalmente (párrafo $4^{\circ}$ del Preámbulo).

De acuerdo con este pronunciamiento del Consejo Constitucional, el Consejo de Ministros presenta ante las Cámaras, para su tramitación conforme al art. 89 de la Constitución, un «proyecto de ley constitucional relativo a los Acuerdos internacionales en materia de derecho de asilo». En su exposición de motivos, se hacía referencia a los Acuerdos de Schengen, así como a la posición mantenida al respecto por el Consejo Constitucional, confirmando así su papel decisivo como factor originario de esta revisión constitucional. Se hacía referencia, asimismo, en la exposición de motivos, a la necesidad de compaginar una regulación del derecho de asilo acorde con la nueva situación creada por el proceso de integración europea y los Acuerdos de Schengen y, al mismo tiempo, a "la tradición republicana de acogida de todos los perseguidos por su acción a favor de la libertad» que ha dado lugar a que la República francesa ostente el título de tierra de asilo. ${ }^{34}$

El proyecto de ley constitucional que comentamos se limitaba a plantear la adición de un nuevo artículo (53-1) que diese acogida a la nueva situación sobrevenida tras los Acuerdos de Schengen. En él se habilitaba a la República para concluir Acuerdos con otros Estados europeos, vinculados por compromisos idénticos en materia de asilo (así como de protección de los derechos humanos y de las libertades fundamentales), relativos a la determinación de sus competencias respectivas en el examen de la demanda de asilo que les sean presentadas (en clara alusión a los Acuerdos de Schengen). Por otra parte (segundo párrafo), al margen de los Acuerdos de Schengen, se facultaba a «las autoridades de la República para otorgar asilo a todo extranjero perseguido por su acción a favor de la libertad o que solicite la protección de Francia por cualquier otro motivo.»

El nuevo artículo adicional (53-1) resultante de la revisión constitucional se ubicaba, en el proyecto de ley constitucional, en el Tit. VI, relativo a Los Tratados y Acuerdos Internacionales. Esta ubicación constitucional fue, no obstante, objeto de controversia al estimar el Consejo de Estado ${ }^{35}$ que la localización de la

33 Se trataba, en concreto, de ocho artículos de la ley relativa a «la regulación de la inmigración y a las condiciones de entrada, acogida y estancia de los extranjeros en Francia» que el Consejo Constitucional, en su Decisión 93-325, de 13 de Agosto de 1993, estimaba que colisionaban con la Constitución, añadiendo, además, que otros seis planteaban serias reservas de constitucionalidad.

34 Tanto la referida exposición de motivos del proyecto de ley constitucional como la posición del Consejo Constitucional, recogida en la mencionada Decisión, y la del Consejo de Estado (Avis de 23 de Septiembre de 1993) pueden verse en Les révisions de la Constitution de 1958, op. cit., pag. 26

35 Avis de 16 de Octubre de 1993; sobre este pronunciamiento del máximo órgano consultivo francés, vid. Les révisions de la Constitution de 1958, pag. 27 
nueva disposición constitucional debía situarse en el Título XV, relativo a la Unión y las Comunidades Europeas, añadiendo una referencia expresa a «los Tratados y Acuerdos con los Estados europeos» y, así mismo, un nuevo art. 88-5 que acogiese la nueva disposición constitucional (con el mismo contenido que e del art. 53-1). Se estimaba por parte del Consejo Constitucional que la nueva disposición a añadir tenía mejor encaje en el Tit. XV relativo a la Unión Europea, ya que estaba originada y vinculada al proceso de integración europea, que en el Tit. VI, referido genéricamente a los Tratados y Acuerdos Internacionales. En cualquier caso, tras la tramitación del proyecto de ley constitucional en las Cámaras, prevaleció la posición inicial manteniéndose la ubicación y numeración originarias (Tit. VI, art. 53-1); igualmente se mantuvo también la redacción inicial, sin que la tramitación parlamentaria (como suele ser usual) ocasionase modificaciones en el texto originario.

Dos cuestiones es preciso comentar en relación con esta nueva disposición constitucional (art. 53-1) insertada por la revisión de 1993. En primer lugar, por lo que se refiere a la cobertura que proporciona a la República para concertar Acuerdos que determinen las competencias sobre las demandas de asilo que se planteen, es preciso puntualizar, a este respecto, que los Estados con los que la República francesa pueda concertar Acuerdos vienen determinados por un doble criterio: geográfico y político. De conformidad con el primero, sólo con los Estados europeos se pueden concertar los referidos Acuerdos; pero es preciso tener en cuenta que la noción de Estado europeo abarca países que no forman parte de la UE (por ej., Suiza o Noruega; o incluso Suecia o Finlandia en el momento en que se aprueba esta revisión constitucional); y plantea problemas en algunos casos: ¿son Turquía, Rusia o Armenia países europeos?. Conviene tener presente que lo europeo no es una noción jurídica y, a falta de ella, quizá la pertenencia al Consejo de Europa sea lo más aproximado. En cualquier caso, corresponderá al Consejo Constitucional decir la última palabra en caso de litigio sobre si un Acuerdo con otro país cumple el requisito geográfico de la europeidad.

El segundo criterio para poder concertar Acuerdos de conformidad con el nuevo art. 53.1, hace referencia a los Estados (europeos) vinculados por idénticos compromisos (que los de la República francesa) en materia de asilo, así como también de protección de los derechos humanos y de las libertades fundamentales. Ello nos remite a la legislación internacional sobre la materia en estas áreas, ${ }^{36}$ que es la que delimita el espacio común (europeo) en el que las au-

36 En materia de asilo, la Convención de Ginebra de 1951 sobre el estatuto de los refugiados, la de Nueva York de 1954 sobre apátridas y el Protocolo de 1967 relativo también al estatuto de los refugiados: por lo que se refiere a los derechos fundamentales, la Convención europea (de 11 
toridades de la República (francesa) pueden concertar acuerdos con los referidos Estados.

La otra cuestión (segundo párrafo del nuevo art. 53.1) hace referencia a la «reserva de soberanía» de la República francesa en materia de asilo. Hay que reseñar la amplitud con que es contemplado el derecho de asilo, que rebasa la previsión preambular (par. $4^{\circ}$ ) — «todo hombre perseguido en razón de su actividad a favor de la libertad...»- para extenderse también a "todo extranjero ... que solicite la protección de Francia por cualquier otro motivo", en consonancia con la concepción sobre la situación de refugiado que hace la Convención de Ginebra: «cualquiera que tema ser perseguido por razón de raza, religión, nacionalidad, pertenencia a un determinado grupo social o por sus opiniones políticas.» Aunque, en los términos en que está redactada la nueva disposición constitucional que comentamos, la protección abarcaría también a toda persona necesitada de ella, más allá de la definición clásica de refugiado. ${ }^{37}$

\section{EL TRATADO DE AMSTERDAM, LA LIBRE CIRCULACIÓN DE PERSONAS Y LA INTERVENCIÓN DE LAS CÁMARAS PARLAMENTARIAS}

1. La firma del Tratado de Ámsterdam (1997) va a originar una nueva revisión constitucional, en 1999, con el fin de dar cobertura a la transferencia de competencias a favor de las instituciones comunitarias europeas que el referido Tratado preveía. En esta ocasión, las materias que pasaban a integrar el ámbito competencial comunitario, de acuerdo con el nuevo Título añadido en Ámsterdam al Tratado de la Comunidad Europea se extendían a «los visados, asilo, inmigración y otras políticas relacionadas con la libre circulación de personas». ${ }^{38}$ Sobre ellas podrían decidir, a partir de la entrada en vigor del Tratado, las instancias europeas —el Consejo- por mayoría cualificada y mediante el pro-

de Abril de 1950, Roma) para la protección de los derechos humanos y de las libertades fundamentales.

37 Sobre el derecho de asilo en esta revisión constitucional, vid. D. MAUS: «Le droit d'asile et la révisión constitutionnelle du 25 Novembre 1993", Revue Française de Droit Constitutionnelle, no 17, 1994, pag. 87

38 Tit. IV (anteriormente Tit. III A) del TCE: arts 61-69; añadido por el art. 2.15 del Tratado de Ámsterdam. Un breve comentario, en el marco de las novedades introducidas en Ámsterdam (1997) en el Tratado de la Unión Europea, puede verse en A. MANGAS MARTIN: «Estudio preliminar. La Unión Europea: del Tratado de Maastricht al Tratado de Ámsterdam», Tratado de la Unión Europea. Tratados constitutivos de las CC.EE., Tecnos, Madrid, 1998, pags. 21-52. 
cedimiento de codecisión en los términos que el propio Tratado precisaba (art. 251 TCE).

$\mathrm{Al}$ igual que ocurrió con la anterior revisión originada por el Tratado de Maastricht, el Consejo Constitucional, en esta ocasión a requerimiento conjunto del Presidente de la República y del Primer Ministro (en ese momento, J. Chirac y L. Jospin, respectivamente), estima que algunas de las disposiciones del Tratado sobre las materias reseñadas colisionaban con la Constitución, haciendo necesaria su revisión para evitar la incompatibilidad entre ambos. Se argumentaba, en este sentido, que "las condiciones esenciales del ejercicio de la soberanía» (empleando idénticos términos que con motivo del Tratado de Maastricht; ver supra) se ven sustancialmente afectadas por la aplicación del procedimiento de codecisión y de las mayorías cualificadas en el Consejo en materia de paso de las fronteras interiores (de la Comunidad europea), de control de las fronteras exteriores, de inmigración, asilo y de concesión de visados, materias todas ellas sustraídas a la competencia exclusiva de los Estados miembros de la Unión en virtud de las cláusulas contenidas en el Tratado de Ámsterdam.

Es preciso puntualizar, no obstante, siguiendo la argumentación del Consejo Constitucional, ${ }^{39}$ que el criterio de (in)constitucionalidad no era tanto el hecho de la ampliación competencial a favor de la Unión Europea como el ejercicio de las competencias transferidas, de acuerdo con las mayorías cualificadas y el procedimiento de codecisión previstos en el Tratado de Ámsterdam. A este respecto, el Consejo Constitucional llama la atención sobre la pérdida del control por parte de los Estados miembros, una vez transcurrido el periodo transitorio de cinco años previsto en el Tratado, sobre las materias transferidas, que pasan a integrar el ámbito de decisión propio de las instituciones comunitarias europeas en los términos fijados en el Tratado de la UE de Ámsterdam. Y ello sí incide de forma determinante en "las condiciones esenciales de ejercicio de la soberanía» haciendo necesaria la revisión constitucional.

Esta Decisión del Consejo Constitucional centra la cuestión en las modalidades de ejercicio de las competencias transferidas a las instituciones europeas, más que en el hecho de la transferencia en sí misma, que tendría cobertura constitucional si se mantuviese la regla de la unanimidad como venía ocurriendo hasta ese momento. Por el contrario, la introducción del procedimiento de codecisión y de las mayorías cualificadas en la regulación por los órganos comunitarios, en particular el Consejo, de las materias transferidas afecta

${ }^{39}$ Decisión no 97-394 DC 31 décembre 1997. Un comentario sobre esta Decisión del Consejo Constitucional puede verse en P. BON: «El Tratado de Amsterdam ante el Consejo Constitucional francés", Revista Española de Derecho Constitucional (REDC), no 53, 1998, pag. 237 y ss. 
a las condiciones esenciales de ejercicio de la soberanía, lo que exige una revisión constitucional. ${ }^{40}$

2. De acuerdo con este pronunciamiento del Consejo Constitucional, el Presidente de la República ejerce de nuevo la iniciativa de revisión presentando un proyecto de ley constitucional que, inicialmente, se limitaba a añadir un nuevo párrafo complementario en el art. 88.2 (introducido en la anterior revisión de 1992, con motivo del Tratado de Maastricht; ver supra). En él se preveía, bajo la reserva de reciprocidad ya contemplada también en la anterior revisión de 1992 y de acuerdo con las modalidades previstas en el Tratado de Ámsterdam, la posibilidad de que «puedan ser consentidas las transferencias de competencias necesarias para la determinación de las normas relativas a la libre circulación de personas y las materias relacionadas.» Se trata de una enmienda complementaria de adición, previendo un supuesto nuevo - determinación de las normas relativas a la libre circulación de personas - al compás de la evolución expansiva del ámbito competencial comunitario en los términos acordados en el Tratado de Ámsterdam (1997).

Interesa llamar la atención sobre el método seguido por el legislador constitucional francés, procediendo a realizar una revisión puntual y limitada ante cada nueva transferencia competencial a favor de las instituciones comunitarias europeas (el Consejo, en particular) y renunciando a introducir una «cláusula general europea» que dé cobertura a cualquier transferencia competencial futura, como ocurre en otros países, entre ellos el nuestro. ${ }^{41}$ La razón de ello, a juicio del legislador constitucional francés, reside en que así se obliga a las Cámaras, en particular, a efectuar un seguimiento de cada uno de los pasos que sigue el proceso de integración europea, garantizando su control en todo momento por parte de la representación nacional francesa. Ello explica, por otra parte, el elevado número de revisiones constitucionales que han venido sucediéndose en estos últimos años (siete entre 1992 y 2008) en relación con esta cuestión.

${ }^{40}$ Vid. F. LUCHAIRE: «Le Traité d'Amsterdam et la Constitution», Revue de Droit Public et Science Politique, 1998, pag. 331 y ss.

${ }^{41}$ Art. 93 de nuestra Constitución, redactado cuando ya se preveía nuestro ingreso en las Comunidades Europeas, proporciona cobertura expresa a «la celebración de tratados por los que se atribuya a una organización o institución internacional el ejercicio de competencias derivadas de la Constitución». En Alemania, el art. 23 de la Ley Fundamental de Bonn, ha sido reformado para hacerla compatible con el proceso de integración europea: «...la Federación podrá transferir derechos de soberanía por una ley que requiere la aprobación del Bundesrat.» Italia, de acuerdo con la redacción originaria del art. 11, que no ha hecho falta modificarla, «acepta, en condiciones de paridad con los demás Estados, las limitaciones de soberanía necesarias para crear un ordenamiento que asegure la paz y la justicia entre las naciones; promueve y favorece las organizaciones internacionales tendentes a tal fin.» 
Inicialmente, el proyecto de ley constitucional (de artículo único) presentado a las Cámaras se limitaba a la inclusión (en el art. 88-2, introducido por la revisión de 1992; ver supra) del nuevo supuesto referido a la libertad de circulación de las personas entre los Estados miembros de la UE. Esta propuesta fue aprobada sin modificaciones, en los términos en que fue formulada inicialmente, por las Cámaras reunidas en Congreso conforme al procedimiento de revisión constitucional previsto en el art. 89. Pero simultáneamente, la tramitación parlamentaria del referido proyecto de ley constitucional dio lugar a la inclusión de nuevas previsiones constitucionales; en particular, por lo que se refiere a la ampliación del control por parte de las instituciones nacionales sobre los actos comunitarios.

3. Así, la revisión constitucional de 1999 introduce una nueva modificación, mediante una enmienda de adición, en otra de las disposiciones (art. 88-4) integrantes de la anterior revisión de 1992. En este caso para reforzar la participación de las Cámaras parlamentarias en los procesos de decisión de las instituciones europeas. Si el art. 88-4, en su versión inicial de 1992, preveía que el Gobierno debía poner en conocimiento de las Cámaras toda propuesta de acto comunitario «que comporte normas de carácter legislativo», la revisión de 1999 amplía esa intervención a «cualquier proyecto o proposición de acto, así como a todo documento que emane de una institución de la Unión Europea»; cuestiones, todas ellas, sobre las que las Cámaras pueden fijar su posición a través de una resolución votada en el pleno. ${ }^{42}$

Como ya se ha indicado, no estaba previsto en el proyecto inicial de ley constitucional presentado a las Cámaras la modificación de esta última disposición constitucional (art. 88-4), introducida también por la reciente revisión de 1992. Fue en el curso de la tramitación parlamentaria cuando se estimó conveniente completar esta disposición constitucional incluyendo en ella una referencia a otros nuevos supuestos de control parlamentario sobre los actos comunitarios. Se justifica, así, la enmienda de adición introducida en el art. 88-4, dada la extraordinaria importancia que tienen, de hecho, algunos documentos de trabajo, o de carácter programático (se menciona, entre otros, la Agenda 2000) aunque no tengan "naturaleza legislativa», que era el único supuesto previsto en la redacción inicial (1992) del art. 88-4.43

42 Sobre esta nueva disposición constitucional, en particular, vid. B. RULLIER: «L'application de l'article 88-4 de la Constitution", Revue Française de Droit Constitutionnel, no 35, 1998, pag. 651 y ss.

43 Vid. Rapport de la Comisión des lois de L'Assemblée Nationale, en Les révisions de la Constitution de 1958, op. cit., pag. 38 
La enmienda de adición introducida era, por otra parte, coherente con las innovaciones introducidas por el Tratado de Amsterdam; en particular, por lo que se refiere al nuevo papel que en él se atribuye a los Parlamentos nacionales en la Unión Europea, tema al que por primera vez se le dedica un Protocolo específico ${ }^{44}$. Así mismo, la nueva redacción del art. 88-4 proporcionaba cobertura constitucional a la intervención del Parlamento en el ámbito propio de las materias relativas a los dos nuevos pilares (según el léxico empleado en el lenguaje eurocomunitario para referirse a las áreas de justicia e interior y de exteriores y defensa) en los que se asienta, de acuerdo con los Tratados de la UE, la construcción europea; materias cuya regulación no estaba basada en normas «de naturaleza legislativa».

Esta revisión constitucional, al igual que todas las relacionadas con la participación de Francia en la Unión Europea, fue aprobada por el Parlamento, reunido en Congreso, de acuerdo con el procedimiento previsto en el art. 89. No faltaron, sin embargo, propuestas, provenientes principalmente desde los sectores más críticos con la forma en que se desarrollaba el proceso de integración europea, que abogaban por someter la revisión a referéndum, opción también prevista en la misma disposición constitucional; se argumentaba para ello que se trataba de una revisión que incidía de lleno en las condiciones de ejercicio de la soberanía nacional, tal y como había señalado el Consejo Constitucional en su Decisión y como reconocía la propia exposición de motivos del proyecto de ley constitucional. Ello no impidió, en cualquier caso, que la revisión fuese aprobada sin mayores problemas en ambas Cámaras y, finalmente, reunidas éstas en Congreso, por una amplia mayoría ${ }^{45}$ que sobrepasaba holgadamente los tres quintos de los votos exigidos constitucionalmente.

Una vez efectuada la revisión constitucional en los términos reseñados, las Cámaras parlamentarias aprobaron poco después la correspondiente ley autorizando la ratificación del Tratado de Ámsterdam, ${ }^{46}$ que daba continuidad al proceso emprendido con el Tratado de Maastricht (1992). Tiene interés llamar la atención sobre el hecho de que el legislador francés no se limitaba en esta ley

${ }^{4}$ Protocolo sobre el cometido de los Parlamentos nacionales en la Unión Europea, incorporado por el Tratado de Ámsterdam (1997)

45 En la Asamblea Nacional fue aprobada, el 1 de diciembre de 1998, por 469 votos a favor, frente a 66 en contra. En el Senado, el 17 de diciembre, por 240 votos a favor, frente a 34 en contra. Finalmente, fue aprobada por el Congreso, el 18 de Enero de 1999, por 759 votos favorables (la mayoría requerida de $3 / 5$ se cifraba en 522) frente a 111 en contra. Ley constitucional no 9949, de 25 de enero de 1999 (Journal Officiel de 26 de Enero). cional.

${ }^{46}$ Ley no 99-229, de 23 de Marzo, una vez efectuada, dos meses antes, la revisión constitu- 
a la simple autorización, como suele ser lo usual, para la ratificación del referido Tratado de Ámsterdam sino que en esta ocasión, además, se compromete expresamente, con un espíritu netamente europeísta, a impulsar «progresos sustanciales, en la vía de la reforma de las instituciones de la Unión Europea», adoptando así una posición activa en el proceso de integración europea.

\section{LA ORDEN DE DETENCIÓN EUROPEA Y LA COOPERACIÓN JUDICIAL EN LA UE}

1. Una nueva revisión constitucional tendrá lugar en 2003, en esta ocasión para proporcionar cobertura constitucional a la orden de detención europea, acordada pocos meses antes en el Consejo de la UE. ${ }^{47}$ De acuerdo con esta Decisiónmarco, los Estados miembros de la UE (quince en aquel momento; no se había producido todavía la ampliación de los países del Este) se comprometían a ejecutar, sobre la base del principio del reconocimiento mutuo, las órdenes de detención provenientes de cualquiera de ellos. La propia Decisión-marco se ocupaba de definir la orden de detención europea como «una decisión judicial emitida por un Estado miembro sobre el arresto o la entrega por otro Estado miembro de una persona perseguida con motivo de una causa penal o para la ejecución de una pena o de una medida de seguridad privativa de libertad.» (art. 10).

Si bien el origen inmediato de la revisión de 2003 (que guarda una relación de continuidad con las anteriores ya reseñadas de 1992, 1993 y 1999, todas ellas originadas por el desarrollo del proceso de integración europea) es la referida $D e-$ cisión-marco del Consejo de la UE, éstas deben ser encuadradas en el marco más amplio del proceso de progresiva delimitación de un espacio de libertad, seguridad y justicia en los términos previstos en el Tratado de Ámsterdam, ${ }^{48}$ ratificados posteriormente en el Tratado de $\mathrm{Niza}^{49}$ que, en esta cuestión, mantiene la misma

47 Decisión-marco 2002/584 sobre la orden de detención europea, adoptada por el Consejo de la Unión Europea el 13 de junio de 2002. Sobe el lugar que va a ocupar esta Decisión en el debate sobre la revisión constitucional de 2003, vid. Les révisions de la Constitution de 1958, po. Cit., pag. 46-47.

48 Tit. VI del Tratado de la Unión Europea (arts. 29 y ss.), de acuerdo con las modificaciones introducidas por el art. 1.11 del Tratado de Âmsterdam (1997), en relación con el Protocolo por el que se integra el Acervo Schengen en el marco de la UE (Protocolo anejo al Tratado de la Unión Europea y al Tratado constitutivo de la Comunidad Europea).

49 Tratado de Niza, de 26 de febrero de 2001; un breve comentario introductorio de conjunto sobre las novedades introducidas en Niza, puede verse en A. MANGAS MARTIN: «Estudio preliminar...». Tratado de la Unión Europea, Tecnos, 2003, pags. 21-50. 
orientación. Se hace referencia en ellos a la necesidad de «una acción en común entre los Estados miembros en los ámbitos de la cooperación policial y judicial en materia penal» (art. 29 TUE); así como también de conseguir «la compatibilidad de las normas aplicables en los Estados miembros, en la medida necesaria para mejorar la cooperación» (art. 31 TUE).

En este contexto, un hecho decisivo como los acontecimientos ocurridos en Nueva York el 11 de Septiembre de 2001, servirá para activar el proceso de cooperación policial y judicial ya contemplado en los referidos Tratados de la UE. Ello va a suponer la aceleración del proceso emprendido en este marco, que ya contaba con antecedentes significativos; cabe mencionar, a este respecto, el Consejo europeo de Tampere, ${ }^{50}$ que ya se había ocupado, poco después de la firma del Tratado de Ámsterdam, del tema. Pero será la situación que sucede a los atentados del 11-S la que va a hacer que las medidas, hasta entonces solo esbozadas, vayan a tener materialización efectiva, como ocurre con la orden de detención europea. ${ }^{51}$

2. En este nuevo escenario, común a los países de la UE, ${ }^{52}$ el gobierno francés adopta las medidas conducentes a la trasposición al propio ordenamiento jurídico de la referida Decisión-marco sobre la orden de detención europea; la primera de ellas, verificar, antes de elaborar el correspondiente proyecto de ley, si existe algún obstáculo constitucional para ello. A tal efecto, el Gobierno se dirige al Consejo de Estado para que éste se pronuncie sobre la cuestión. Interesa llamar la atención sobre el hecho de que sea el Consejo de Estado, y no el Consejo Constitucional como había ocurrido en anteriores revisiones, el organismo ante el que se plantea el asunto. Ello es debido, como se especifica en la propia exposición de motivos del proyecto de ley constitucional, a que la cuestión planteada no tiene encaje en el art. 54 de la Constitución, que es el que prevé la intervención del Consejo Constitucional, ya que ésta se ciñe al supuesto de los compromisos internacionales sometidos a ratificación, lo que no es el caso de la Decisión marco sobre la orden de detención europea.

En su respuesta al requerimiento del Gobierno, el Consejo de Estado estimaba que si bien la Decisión-marco sobre la orden de detención europea no era

50 El Consejo europeo celebrado el 15-16 de Octubre de 1999 en la ciudad finlandesa de Tampere, bajo la presidencia de este país, es el punto de partida que conduce a la posterior adopción de la orden de de detención europea.

51 Vid., referido al conjunto de los Estados miembros, en general, Oreste POLLICINO: "Mandato di arresto europeo e principi costituzionali degli Stati membre», Diritto Pubblico Comparato ed Europeo, 2008-II, pag. 1001 y ss.

52 En España, en particular, Ley 3/2003, de 14 de Marzo (BOE de 17 de Marzo de 2003), sobre la orden europea de detención y entrega 
inconstitucional sí era necesario, sin embargo, clarificar un punto que podía inducir a confusión; se trataba, en concreto, del "principio según el cual el Estado debe reservarse el derecho a rechazar la extradición por infracciones que considere son de carácter político", ${ }^{53}$ lo que constituye, prosigue el Consejo de Estado, un principio fundamental recogido en el preámbulo constitucional. Es por ello por lo que es conveniente, con el fin de evitar confusiones al respecto, proceder a una revisión de la Constitución sobre esta cuestión, antes de realizar la trasposición de la Decisión-marco sobre la orden de detención europea.

De acuerdo con las indicaciones del Consejo de Estado, el Gobierno elabora un proyecto de ley constitucional, integrado por un breve artículo único, que se limitaba a añadir un nuevo párrafo al art. 88.2 (introducido, como ya se ha visto, en la revisión de 1992 y modificado, en los términos también vistos, en la revisión de 1999; ver supra). Se trata de una enmienda de adición, que no modifica en nada ni los párrafos precedentes del mismo artículo (88-2) ni ninguna otra disposición del Título relativo a la UE, que introduce una cláusula habilitadora a favor del Parlamento, tal y como puntualiza la exposición de motivos (párrafo final), en virtud de la cual se reserva a la ley la determinación de las normas relativas a la orden de detención europea.

En su redacción originaria, el proyecto de ley constitucional propuesto por el Gobierno hacía referencia expresa a «las Decisiones-marco adoptadas por el Consejo de la Unión Europea», lo que permitía garantizar la trasposición al derecho interno de todos los actos jurídicos de esa naturaleza que pudieran en lo sucesivo completar o modificar la Decisión-marco de 13 de Junio de 2002 sobre la orden de detención europea. Como se puso de manifiesto en la discusión parlamentaria en la Asamblea Nacional, era la primera vez que el Gobierno optaba por una fórmula que constitucionalizaba a priori los eventuales cambios constitucionales que pudieran derivarse de los actos jurídicos adoptados por el Consejo de la UE, en contra de la posición mantenida hasta ese momento, que exigía un examen específico, en cada caso, de la constitucionalidad de los compromisos internacionales contraídos. ${ }^{54}$ Finalmente, en su redacción

53 Exposición de motivos (párrafo séptimo) del proyecto de ley constitucional relativo a la orden de detención europea (texto reproducido en Les révisions de la Constitution de 1958, op. cit., pag. 45).

54 Se alude expresamente a la posición mantenida a propósito de la revisión constitucional originada por la firma del Tratado de Roma (18 de julio de 1998) por el que se instituía el Tribunal Penal Internacional (TPI). En esta ocasión, en el debate en la Asamblea Nacional sobre la revisión constitucional, el ponente, M. Alain Vidalies, sostenía que «toda modificación del Tratado [de Roma, sobre el TPI] requiere una nueva revisión constitucional", Les révisions de la Constitution de 1958, op. cit., pag. 46. 
final, se eliminaba la referencia específica a las decisiones-marco, sustituyéndola por otra más genérica que aludía a «los actos adoptados en base al Tratado de la Unión Europea»

Por lo que se refiere a la ubicación de la nueva disposición introducida por esta enmienda constitucional, se optó por añadir un párrafo adicional (tercero) al art. 88-2, en vez de ubicarla en un artículo separado. Se argumentaba para ello ${ }^{55}$ que en la medida en que la decisión-marco sobre la orden de detención europea constituye un acto comunitario derivado basado en el TUE, al que hace referencia expresa y reiterada el art. 88-2, resulta lo más lógico su ubicación en este lugar. Posición que, es preciso advertir, si entonces (2003) es la que fue asumida en la Asamblea Nacional, posteriormente (2008) será modificada, reubicando separadamente esta disposición (aunque manteniendo su numeración: art.88.2), dada la problemática específica que plantea, en relación con otras materias, todo lo relativo a la orden de detención europea.

Como se puso de manifiesto en el curso del debate parlamentario, se trataba de una revisión constitucional que incidía sobre asuntos que trascendían el ámbito relativo al mercado (y también el de la mera integración económica) para adentrase en el terreno más sensible de las cuestiones que conectan con la soberanía nacional. Es ilustrativo, al respecto, la polémica suscitada, en torno a la orden de detención europea, sobre el derecho que debe reservarse el Estado para denegar las extradiciones por motivos políticos, tal y como recordaba en su pronunciamiento el Consejo de Estado (ver supra); o también las posiciones más radicalmente críticas de quienes llegaban a sostener que con esta revisión el principio de soberanía nacional quedaba seriamente afectado al perder el Estado un instrumento típico como es el control de las extradiciones; en especial cuando se trata de motivos políticos.

En cualquier caso, la ley constitucional fue finalmente aprobada por una amplísima mayoría que rozaba casi el $95 \%$ de los votos del Congreso (826 votos favorables sobre 875 ). Tan sólo el minoritario grupo comunista y republicano (44 miembros: 21 en la Asamblea Nacional y 23 en el Senado), que también se había opuesto a las anteriores revisiones constitucionales, mantuvo una posición contraria (acompañado de algunos miembros dispersos de los grupos mayoritarios). Hay que advertir, sin embargo, que esta aplastante mayoría favorable a la revisión constitucional no volverá a repetirse en las siguientes.

55 Rapport de la Comisión legislativa de la Asamblea Nacional en el debate en esta Cámara sobre la revisión constitucional, op. cit., pag. 46. 


\section{EL FRUSTRADO PROYECTO DE TRATADO CONSTITUCIONAL DE LA UE. LA «CLÁUSULA TURCA»}

1. El proyecto de Tratado por el que se establece una Constitución para Europa ${ }^{56}$ va a abrir, una vez más, un nuevo proceso de revisión constitucional. En esta ocasión, sin embargo, el hecho que origina la revisión presenta características especiales ya que se trata de un Tratado europeo que, a diferencia de los anteriores (Maastricht, Ámsterdam, Niza), afirma explícitamente su carácter constitucional. Ello plantea la cuestión en términos distintos a los que se había venido planteando hasta ese momento; en particular, por lo que se refiere a las relaciones y a la compatibilidad entre los Tratados europeos, que ahora son de naturaleza constitucional, y las Constituciones de los Estados miembros; en el caso que nos ocupa, de la República francesa.

Antes de entrar en el examen de las cuestiones de carácter estrictamente constitucional, es preciso hacer una referencia previa al amplio debate político que tuvo lugar en Francia con motivo del proyecto de Tratado constitucional europeo. ${ }^{57}$ A diferencia de otros países (entre ellos, muy señaladamente, el nuestro), donde apenas hubo debate político y el tema pasó casi desapercibido para la opinión pública, Francia fue quizá el país europeo en el que este asunto despertó mayor interés y también el que con mayor intensidad se movilizó y se polarizó en torno a él. Sin duda, muy superior al de los Tratados precedentes (Maastricht, Ámsterdam, Niza) que si bien no puede decirse que pasaron desapercibidos, como en gran medida ocurrió en otros países, no alcanzaron en ningún caso el grado de movilización y de polarización que se produjo con motivo del Tratado constitucional de la UE.

A ello contribuyó, de forma decisiva, el referéndum que se convocó al efecto, en cuyo marco se produjo un amplio debate nacional y una movilización ciudadana que tuvo su expresión en el elevado nivel de participación del electorado. ${ }^{58}$ Como ya es conocido, la cita referendaria se saldó con un rechazo al

56 Tiene su origen en el Consejo Europeo, reunido en Laeken (Bélgica) el 14 y 15 de diciembre de 2001, que encomienda a una Convención Europea la elaboración de un proyecto constitucional para la Unión Europea. Este proyecto será «adoptado por consenso» en el seno de la Convención y presentado al Consejo Europeo, reunido en Salónica, el 20 de Junio de 2003. Finalmente, fue suscrito en Roma el 29 de Octubre de 2004.

57 Sobre este tema, vid. A.J. SÁNCHEZ NAVARRO: «El debate sobre el Tratado por el que se establece una Constitución para Europa en Francia», Teoría y Realidad Constitucional (TRC), no 15, 2005, pags. 365-383

58 Sobre un censo electoral de 41.789.202 electores, votaron 28.988.300, lo que supone una participación que roza el 70\% (69,3 exactamente); contrasta esta elevada participación en Francia 
proyecto de Tratado constitucional que no sólo tuvo efectos internos, impidiendo que éste pudiese ser suscrito por la República francesa, sino que, además, supuso (junto con la negativa holandesa, pocos días después) el fin del proceso constitucional que venía desarrollándose en torno a este proyecto de Tratado. La frustración de este proceso dará paso, a continuación, a la apertura de un nuevo periodo que culminará poco después con el Tratado de Lisboa.

2. Como en otras ocasiones, el texto del proyecto de Tratado constitucional fue sometido (de acuerdo con el art. 54 C.) a la consideración del Consejo Constitucional para que éste se pronunciase sobre su compatibilidad con la Constitución y las modificaciones que, en su caso, sería necesario introducir. Llama la atención la rapidez con la que se pronuncia el Consejo Constitucional (19 de noviembre, 2004), antes de que transcurra siquiera un mes desde la firma del proyecto de Tratado constitucional en Roma (29 de octubre, 2004). Se daba cumplimiento así, con una celeridad poco común, al trámite inicial que despejaba el camino para la elaboración del proyecto de ley constitucional y su presentación en las Cámaras para su discusión parlamentaria en ellas.

El Consejo Constitucional59 aborda una amplia serie de cuestiones que presentan el mayor interés desde el punto de vista constitucional ya que en esta ocasión, a diferencia de las anteriores, el Tratado sobre el que debe pronunciarse tiene carácter constitucional. Cabe mencionar entre las cuestiones sometidas a la consideración del Consejo Constitucional, las relativas a la primacía del derecho de la Unión, al alcance de los derechos fundamentales recogidos en el proyecto de Tratado constitucional (incorporados desde el Tratado de Niza, 2001), las disposiciones relativas a las políticas y al funcionamiento de la Unión, en cuyo caso, se precisa, «requieren reforma constitucional las cláusulas del Tratado que transfieran a la Unión competencias que afecten a las condiciones esenciales de ejercicio de la soberanía» (reiterando los términos y la expresión ya conocida utilizada en ocasiones precedentes). Así mismo, se examina también la incidencia constitucional de los nuevos procedimientos legislativos (en particular, el denominado de codecisión) y el alcance del principio de subsidiariedad. Finalmente, se examinan las nuevas prerrogativas reconocidas a los Parlamentos nacionales en el marco de la Unión.

De acuerdo con las observaciones formuladas por el Consejo Constitucional ${ }^{60}$ el Gobierno elabora el correspondiente proyecto de ley constitucional.

con el $43 \%$ de participación en nuestro referéndum sobre la misma cuestión unos meses antes, en febrero de 2005.

59 Decisión 2004-505, DC de 19 noviembre 2004; un comentario sobre esta decisión del Consejo Constitucional puede verse en A.J. SÁNCHEZ NAVARRO, op. cit., pag. 367 y ss.

${ }^{60}$ Una reproducción sintética de las mismas puede verse en Les révisions de la Constitution de 1958, op. cit., pag. 51-52. 
En él se hacía referencia a tres cuestiones muy diferentes que, además, se preveía que empezasen a tener efectos en momentos también diferentes, en función de la aprobación definitiva del Tratado constitucional que originaba la revisión de la Constitución (es preciso advertir que, finalmente, el Tratado no llegó a aprobarse). Ello obliga a tratar por separado los distintos temas que eran objeto de esta ley constitucional, en buena parte frustrada como se verá a continuación.

El primero de ellos se refería a la introducción, en la disposición que constitucionalizaba la participación de Francia en la UE (art. 88-1, introducido, a su vez, en la revisión constitucional de 1992, con motivo del Tratado de Maastricht) de un párrafo adicional conteniendo una cláusula habilitadora para que la República pueda "participar en la Unión Europea en las condiciones previstas en el Tratado estableciendo una Constitución para Europa, firmado el 29 de Octubre de 2004.» Como se argumentó en la discusión parlamentaria de esta disposición ${ }^{61}$ la generalidad de su enunciado elimina cualquier obstáculo jurídico que pudiera desprenderse de la Decisión del Consejo Constitucional sobre la ratificación del Tratado. En cualquier caso, lo cierto es que una referencia explícita a un Tratado en particular no figuraba en la redacción de esta disposición constitucional (art. 88-1) con motivo de los Tratados anteriores (Maastricht, Ámsterdam, Niza). Sin duda, el carácter constitucional del proyecto de Tratado suscrito en Roma (2004) aconsejaba hacer una referencia explícita con el fin de evitar posibles problemas en el futuro.

Hay que añadir que el propio proyecto de ley constitucional preveía también (art. 3), con una técnica que puede considerarse bastante discutible desde el punto de vista de la claridad y la certeza jurídicas, una nueva redacción distinta del mismo art. 88-1 de la Constitución, una vez que el Tratado constitucional entrase en vigor. En la nueva redacción prevista para el art. 88-1, que introducía correcciones de carácter formal sin afectar al contenido de la misma, se mantenía la referencia explícita, ya mencionada, a «las condiciones fijadas por el Tratado que establece una Constitución para Europa, firmada el 29 de Octubre de 2004»; Tratado que, como ya sabemos, fue rechazado en referéndum por los votantes franceses, ${ }^{62}$ por lo que esta nueva versión del art. 88-1 no llegó a tener vigencia.

3. Además de esta modificación del art. 88-1 en los términos reseñados, otra de las modificaciones que el proyecto de ley constitucional pretendía in-

${ }^{61}$ Vid. Rapport de la Comisión legislativa del Senado, Les révisions de la Constitution de 1958, op. cit., pag. 53.

62 En el referéndum de Mayo de 2005, frente a los 12. 808.270 votos favorables al proyecto de Tratado constitucional, los contrarios ascendieron a 15.499 .508 , lo que supone unos porcentajes del $45,3 \%$ y $54,7 \%$ respectivamente. 
troducir era la reescritura del conjunto del Título XV, relativo a las Comunidades y la Unión europeas, que como ya sabemos había sido introducido por la revisión constitucional de 1992 y había venido experimentando nuevas modificaciones en las sucesivas revisiones efectuadas con posterioridad (1999 y 2003); y que en 2005, cuando volverá a ser modificado nuevamente con motivo del Tratado constitucional, estaba necesitado de algo más que un simple «toilettage». ${ }^{63}$

De acuerdo con el proyecto de ley constitucional presentado inicialmente a la Cámaras, se pretendía no sólo una rectificación de la redacción del texto de las disposiciones que integraban el referido Tit. XV, eliminando expresiones reiterativas producto de la acumulación de modificaciones sucesivas así como términos que habían perdido validez (referencias a las Comunidades Europeas o a los Tratados de la Unión Europea anteriores al Tratado constitucional) sino que también se estimó conveniente aprovechar la ocasión para introducir nuevas disposiciones, a añadir a las ya existentes en el Tit. XV. En este sentido, las nuevas disposiciones proyectadas hacían referencia a la intervención de las Cámaras en dos nuevos ámbitos: por una parte, la posibilidad de controlar la conformidad de los actos legislativos emanados de las instituciones europeas con el principio de subsidiariedad en los términos reconocidos por el Tratado constitucional; y, así mismo, la posibilidad de que el Parlamento pueda «oponerse a una modificación de las normas de adopción de los actos de la Unión Europea según el procedimiento de revisión simplificada (art. IV-444) del Tratado.»

Esta reescritura de las disposiciones integrantes del Tit. XV, relativo a las Comunidades y la Unión europeas, quedaba diferida en el tiempo a la aprobación y entrada en vigor del Tratado constitucional de la UE; ${ }^{64}$ eventualidad que, como es sabido, no llegó a hacerse realidad debido, precisamente, al rechazo del Tratado constitucional en el referéndum francés (y pocos días después, el holandés) de Mayo de 2005. Así pues, la proyectada reescritura del Título XV de la Constitución quedó finalmente excluida de la revisión constitucional de 2005, que se ciñe a la modificación, en los términos señalados, del art. 88-1 y a la introducción, en los términos que se señalará a continuación del art. 88-5. Hay que advertir, sin embargo, que este proyecto de reescritura del Título XV que no

63 Según el expresivo término -cuyo significado viene a ser el de aseamiento o lavado- utilizado en el debate en la Comisión de leyes de la Asamblea Nacional; vid. Les révisions de la Constitution de 1958, op. cit., psg. 52

${ }^{64}$ Se trata de «disposiciones precarias introducidas en la Constitución», según el juicio crítico de Laetitia GUILLOUD: «Révision constitutionnelle et intégration européenne, l'insoutenable légèreté de la Constitution", Revue de Droit Public et Science Politique., pag. 404 y ss. 
pudo llevarse a cabo en la revisión constitucional de 2005 será retomado, con ligeras correcciones, por el legislador constitucional de 2008, formando parte integrante de la revisión constitucional que, con motivo del Tratado de Lisboa (2007), se realizará en 2008.

4. Una mención específica merece la introducción de la nueva disposición constitucional (art. 88.5) relativa a una eventual ampliación de la Unión Europea, exigiéndose en este supuesto que el Tratado de adhesión del nuevo Estado sea sometido a referéndum (en Francia) por el Presidente de la República. Si bien el enunciado de esta nueva disposición no se refiere explícitamente a un país en particular, siendo aplicable, en principio, a cualquiera que pretenda adherirse a la UE, en realidad la nueva disposición constitucional que comentamos tiene un destinatario muy concreto: Turquía (la expresiva denominación con que es conocida, "la cláusula turca», resulta ilustrativa), suponiendo, de hecho, un veto encubierto al ingreso de este país en la Unión Europea. ${ }^{65}$

$\mathrm{Al}$ margen de otras consideraciones políticas que puedan hacerse sobre este veto encubierto a Turquía, resulta muy discutible, desde el punto de vista estrictamente constitucional, la conveniencia de este tipo de cláusulas que proyectan sus efectos fuera del propio ámbito territorial y que van dirigidas $a$ (o, para ser más precisos, contra) otros países, al tiempo que pueden crear serios problemas en las relaciones entre los países integrantes de la Unión. Así, por ej., ¿qué pasaría si otros países miembros de la UE se posicionasen en sentido contrario, a favor de la entrada de Turquía en la UE?. No parece posible consolidar ningún proyecto común entre varios países -27 en el momento actual, a falta de algunos que ya han expresado su intención de adherirse, entre ellos Turquíacon cláusulas unilaterales como la recogida en el nuevo art. 88-5 introducido en esta revisión constitucional.

Por otra parte, esta discutible cláusula obliga al Presidente de la República a convocar un referéndum ante cada nueva adhesión, siendo en la actualidad varios los países balcánicos, además de Turquía, que aspiran a incorporarse a la UE. Esta circunstancia, que es la que realmente se da en la actualidad, ha planteado la necesidad de rectificar esta disposición, en los términos en que fue redactada, para flexibilizar su aplicación; en particular, por lo que se refiere a la obligato-

${ }^{65}$ En diciembre de 1999, la entonces Unión Europea de los quince -no se había producido aun la incorporación de los países de la Europa oriental- acordó aceptar la candidatura de Turquía como miembro de la Unión. A partir de entonces, y durante casi una década ya, se ha desarrollado un complejo y tortuoso proceso negociador con resultado incierto, por el momento; así lo muestra el hecho de que, en el momento actual, previo a las elecciones 2009 al Parlamento europeo, tan sólo uno de los treinta y cinco capítulos objeto de las negociaciones haya sido cerrado. 
riedad del referéndum ante cada nueva adhesión. La última de las revisiones constitucionales (julio 2008) se ha ocupado de ello, eximiendo de la obligatoriedad del referéndum en los supuestos que se indican. ${ }^{66}$

\section{EL TRATADO DE LISBOA Y LA REESCRITURA DEL TIT. XV RELATIVO A LA UE. EL REFORZAMIENTO DEL CONTROL PARLAMENTARIO}

1. El rechazo del Tratado constitucional europeo en el referéndum de mayo de 2005 interrumpió temporalmente el desarrollo del proceso de integración europea, al menos en los términos que preveía el proyecto de Tratado rechazado. Ello obligaba a buscar salidas alternativas, que no estaban previstas a pesar de las profusas elucubraciones en los medios de comunicación sobre un pretendido plan $B$ que, como los hechos se encargaron de poner de manifiesto, no existía. En cualquier caso, el no francés, al que hay que añadir el holandés pocos días después, suponían un golpe decisivo para que el proceso de integración europea se desarrollase en el futuro sobre bases y de acuerdo con criterios constitucionales.

Además de este efecto externo, en relación con la Unión Europea, abortando el proceso de constitucionalización que había abierto el proyecto de Tratado constitucional, también en el ámbito interno el rechazo del Tratado tuvo consecuencias constitucionales de primer orden. La primera y más inmediata, que dejaba sin efecto la anterior revisión constitucional de 2005; en particular, por lo que se refiere a las disposiciones de ésta que hacían referencia al frustrado Tratado constitucional como era el caso del ya mencionado art. 88.1, que en su nueva redacción contenía una alusión expresa a éste. Así mismo, quedaba también sin efecto la reescritura del Tit. XV (algo más que un simple «toilettage» como se dijo en el debate constitucional) que estaba vinculada a la entrada en vigor del Tratado constitucional. ${ }^{67}$ Curiosamente, la única disposición constitucional de la revisión de 2005 que mantuvo sus efectos fue la denominada «cláusula turca» (art. 88.5), que era precisamente la que menos tenía que ver con el Tratado constitucional rechazado y que fue introducida en el curso de la tramitación parlamentaria de la ley constitucional.

${ }^{66}$ Arts. 44 y 47 de la ley constitucional 2008-724, de 23 de julio de 2008 (J.O. de 24 de Julio), modificando el art. 88.5 de la Consitución. (ver infra)

67 Sobre esta cuestión, vid. el juicio crítico de Laetitia GUILLOUD: «Révisión constitutionnelle et intégration européenne, l'insoutenable légèreté de la Constitution», Revue de Droit Public et Science Politique, 2009, pag. 397-424. 
Las consecuencias políticas del rechazo en el referéndum al Tratado constitucional fueron mayores en Francia ya que, a diferencia de otros países en los que apenas hubo debate sobre el tema (nuestro propio caso puede ser muy ilustrativo), en Francia la controversia política fue especialmente intensa, cruzando de forma transversal a la casi totalidad de las fuerzas políticas. Ello originó serias divergencias en su seno (aunque no en todas en la misma medida); tal fue el caso, especialmente, de la principal fuerza de la oposición entonces, el PSF, sobre la que se cernía una crisis política que el resultado del referéndum interno no sólo no cerró sino que incluso la agravó. También, aunque con mucha menor intensidad, en el seno de la mayoría presidencial (UMP), donde también había sectores significativos que se mostraban muy reticentes ante el proyecto constitucional europeo. En cualquier caso, lo cierto es que la amplia mayoría parlamentaria que apoyaba el Tratado constitucional sometido a referéndum fue desautorizada por la clara mayoría (en torno al 55\% frente al 45\%) de votos adversos.

Un factor adicional a tener también muy en cuenta es la coyuntura de relevo presidencial por la que atravesaba Francia tras el referéndum, marcada por la finalización del mandato presidencial de F. Chirac; lo que lastraba las posibles iniciativas que desde la Presidencia de la República pudieran adoptarse para reemprender el camino interrumpido desde el verano de 2005. Esta situación de impasse en el ámbito interno nacional coexistía con la reapertura en la UE de un nuevo proceso negociador para acordar los términos de un nuevo Tratado que reemplazara al recién frustrado por el referéndum y que finalmente culminaría con la firma del Tratado de Lisboa. ${ }^{68}$

2. El relevo presidencial de N. Sarkozy (y, así mismo, la renovación de la Asamblea Nacional) en la primavera de 2007 abría el nuevo escenario que va a hacer posible la continuación del proceso de revisión constitucional interrumpido con el referéndum de 2005. Es preciso reseñar, a este respecto, que uno de los objetivos anunciados por el nuevo Presidente, N. Sarkozy, una vez concluido el doble proceso electoral -presidencial y parlamentario- era la realización de una amplia revisión constitucional. ${ }^{69}$ Ello comportaba abordar sin dilación la asignatura pendiente (desde el verano de 2005) relativa a la adecuación de la Cons-

${ }^{68}$ Suscrito en la cumbre europea celebrada en la capital portuguesa el 13 de diciembre de 2007 y cuya entrada en vigor, una vez ratificado por los Estados miembros, estaba prevista para el 1 de enero de 2009, previsión que no fue cumplida.

${ }^{69}$ Hay que subrayar la prioridad que el nuevo presidente da a la revisión constitucional, anunciada a los pocos días de asumir el cargo presidencial y en el marco de la fiesta nacional francesa del 14 de julio, lo que le confiere mayor solemnidad. 
titución francesa al cambiante marco de la Unión Europea, que acababa de establecer, en su cumbre de Junio de 2007, las bases para un nuevo Tratado, ahora de carácter expresamente no constitucional, ${ }^{70}$ que finalmente tendrá su materialización en Lisboa (diciembre 2007).

Siguiendo el mismo procedimiento (art. 61) ya visto en ocasiones anteriores, el nuevo Presidente de la República somete a la consideración del Consejo Constitucional el nuevo texto suscrito en Lisboa, demandando su pronunciamiento sobre la compatibilidad con la Constitución francesa. En su respuesta, el Consejo Constituciona ${ }^{71}$ estima que la firma del nuevo Tratado de Lisboa exige, a su vez, una nueva revisión constitucional ya que hay cláusulas de éste que pueden colisionar con la Constitución. Se mencionan expresamente, además de las ya mencionadas en otras ocasiones en materia de control de fronteras y de cooperación judicial, las disposiciones del Tratado (de Lisboa) relativas a la aplicación del principio de subsidiariedad.

De acuerdo con esta Decisión del Consejo Constitucional, fue presentado ante las Cámaras el correspondiente proyecto de ley constitucional, aprobado por éstas y, a continuación, por el Congreso sin apenas variaciones, en una rápida tramitación parlamentaria (Enero 2008). Esta rapidez en la tramitación y aprobación de la revisión no debe ocultar, sin embargo, la falta de un acuerdo amplio sobre el texto, que tendrá su plasmación en la sensible reducción, en relación con ocasiones anteriores, de los votos favorables. Aunque también es preciso reseñar que más que de un rechazo frontal al Tratado en sí, se trataba de una dispersión y fraccionamiento de los apoyos como consecuencia de la crisis que con motivo del referéndum se había desencadenado en los partidos políticos (particularmente, en el PSF); lo que va a tener su proyección diferida sobre el Tratado de Lisboa, a pesar de tratarse de un texto diferente.

La ley constitucional finalmente aprobada ${ }^{72}$ constaba de dos partes: en primer lugar, se hacía una referencia expresa al Tratado de Lisboa (2007), sucesor del Tratado constitucional rechazado en el referéndum de 2005. Así, en la primera de las disposiciones (art. 88-1) del Tit. XV, en la que se constitucionalizaba expresamente (desde la revisión de 1992) la participación de la República (francesa) en la Unión Europea (y las CC.EE.), se precisa ahora que esta participación se hará «en las condiciones previstas en el Tratado de Lisboa ... firmado

70 Vid. mi artículo, comentando la cumbre de la UE de junio 2007, «La desconstitucionalización de la Unión Europea», El Correo, 18 de julio de 2007.

${ }^{71}$ Decisión no 2007/560 DC de 20 de diciembre de 2007

${ }^{72}$ Ley constitucional 2008-103 de 4 de febrero de 2008 modificando el Tit. XV de la Constitución 
el 13 de Diciembre de 2007.» Se proporcionaba así cobertura constitucional al Tratado de Lisboa, empleando el mismo método seguido en ocasiones anteriores de hacer una mención explícita del Tratado en el texto constitucional (lo que obviamente comporta una nueva revisión constitucional cada vez que se cambie el Tratado).

3. Además de esta modificación del art. 88-1 en los términos señalados, la ley constitucional que comentamos (art. 2) contenía una reescritura de la casi totalidad del Tit. XV, relativo a la Unión Europea, cuya entrada en vigor estaba condicionada a la propia entrada en vigor del Tratado de Lisboa. ${ }^{73}$ Como se ha indicado anteriormente, ya en el proyecto de ley constitucional de la anterior revisión (2005) con motivo del Tratado constitucional, se había previsto la reescritura del referido Título, cuyas disposiciones habían sido objeto de repetidas revisiones y estaban necesitadas de retoques en su redacción. La frustración del proyecto de Tratado constitucional tras el referéndum de 2005, dejó sin efecto estas previsiones constitucionales, que van a ser retomadas ahora en el marco de la nueva revisión constitucional (Enero 2008) originada por el Tratado de Lisboa.

La reescritura del Tit. XV relativo a la Unión Europea afectaba a cuatro de las cinco disposiciones que le integraban en aquél momento (tras la revisión constitucional de 2005, que había añadido la denominada "cláusula turca» en el nuevo art. 88-5). Tan solo el art. 88-3, relativo a los derechos de sufragio de los ciudadanos de la Unión en las elecciones municipales (ver supra), permanecía invariable, en los mismos términos en que fue redactado en la revisión inicial realizada (1992) con motivo del Tratado de Maastricht. Si bien la reescritura de las restantes disposiciones no introducía cambios de contenido, cabe reseñar, sin embargo, la supresión (en el art. 88.2) de las referencias a las transferencias de las competencias necesarias para el establecimiento de la Unión Económica y Monetaria en los términos previstos en el Tratado de Maastricht (1992); y, así mismo, a las transferencias de las competencias necesarias para la determinación de las normas relativas a la libre circulación de personas, en los términos previstos en el Tratado de Ámsterdam (1997).

Llama la atención en esta reescritura del Tit. XV la repetición, en la misma ley constitucional de revisión, de la modificación (una especie de «remodifica-

${ }^{73}$ Prevista inicialmente, como ya se ha indicado, para el 1 de enero de 2009. No obstante, esta fecha ha sido incumplida debido a las dificultades surgidas en el proceso de ratificación en algunos de los Estados miembros en los que sus dirigentes han hecho gala de su euroescepticismo (hay que mencionar, a este respecto, de forma especial, a los presidentes polaco y checo; este último detentando este semestre la presidencia de la UE); así como también el resultado adverso del referéndum en Irlanda (junio 2008) que ha dado lugar a la convocatoria de un nuevo referéndum en el próximo otoño (2009). 
ción») de la redacción del art. 88.1, ya modificado en esta misma ley para introducir la referencia al Tratado de Lisboa en los términos señalados y vuelto a modificar para refundir la redacción de los dos párrafos de que constaba en uno sólo, sin alterar su contenido. Aunque se trate de cuestiones formales que no afectan al contenido, no deja de ser una técnica jurídica un tanto extraña y, sobre todo, bastante dudosa desde el punto de vista de la claridad y la certeza jurídicas, esta doble redacción de las disposiciones constitucionales reseñadas (88$1,88-2,88-4$ y $88-5) .^{74}$

4. Junto a esta reescritura de las disposiciones indicadas, que no afecta a su contenido, la revisión que estamos comentando (Febrero 2008) introduce dos nuevas disposiciones constitucionales que, en este caso, sí introducen modificaciones de contenido y que pasamos a examinar brevemente a continuación. Hay que advertir, sin embargo, dada la extraña técnica utilizada por el legislador constitucional francés a que acabamos de referirnos, que estas dos nuevas disposiciones constitucionales (arts. 88-6 y 88-7), a pesar de estar publicadas en el Journal Officiel de la Republique, ${ }^{75}$ no tienen vigencia actualmente; y sólo la tendrán a partir del momento en que sea ratificado por los Estados miembros de la Unión Europea el Tratado de Lisboa.

Las dos nuevas disposiciones introducidas por la revisión de febrero de 2008 tienen como finalidad reforzar la posición del parlamento francés en relación con las disposiciones que puedan adoptar, en determinados ámbitos, las instancias decisorias de la Unión Europea. Ambas disposiciones, que figuraban ya en el anterior proyecto de ley constitucional (2005), aunque no llegaron a materializarse en la revisión constitucional de 2005 (limitada a los arts. 88-1 y 885 ; ver supra) son rescatadas ahora por el legislador constitucional de 2008 (febrero), que las incorpora a esta revisión constitucional, si bien difiriendo su vigencia efectiva a la incierta entrada en vigor del Tratado de Lisboa. ${ }^{76}$

La primera de ellas (art. 88-6) tiene como eje la defensa del principio de subsidiariedad, reconocido expresamente en el Tratado de Lisboa (art. 5). A tal fin, la nueva disposición que comentamos proporciona cobertura constitucional

${ }^{74}$ No deja de resultar curioso que el texto oficial de la Constitución francesa, en la versión ofrecida por la Asamblea Nacional (2008) (así como también por la Documentation française) ofrezca dos redacciones no coincidentes de los referidos arts. 88-1, 88-2, 88-4 y 88-5; el asunto se complica más tras la posterior revisión de julio de 2008 , que remodifica algunas de estas disposiciones.

75 J.O. de 5 de febrero de 2008

76 Sobre esta peculiar tipología de «disposiciones precarias introducidas en la Constitución», vid. Laetitia GUILLOUD: «Revisión constitutionnelle et intégration européenne, l'insouteneble légèreté de la Constitution», Revue de Droit Public et Science Politique, 2009, pag. 404 y ss. 
expresa para la intervención de cualquiera de las Cámaras - Asamblea Nacional o Senado-, que pueden emitir un dictamen (Avis) motivado sobre la conformidad de un proyecto de acto legislativo europeo en relación con el mencionado principio de subsidiariedad. Por lo que se refiere al procedimiento, se prevé que sea el Presidente de la Cámara emisora del Avis el que se dirija a los Presidentes del Parlamento Europeo, del Consejo y de la Comisión europea, informando al Gobierno de ello.

Además, y en relación también con el principio de subsidiariedad, se prevé la intervención de cualquiera de las Cámaras para interponer un recurso ante el Tribunal de Justicia de la Unión Europea contra todo acto legislativo europeo que vulnere el referido principio de subsidiariedad. En este caso, el recurso es transmitido al Tribunal de Justicia de la UE por el Gobierno (francés). Finamente, y con el fin de reforzar más aún la intervención de las Cámaras parlamentarias, se prevé que éstas puedan aprobar resoluciones sobre la materia «incluso fuera de las sesiones, según las modalidades de iniciativa y de discusión fijadas en el reglamento de cada Cámara.»

La otra disposición constitucional (art. 88-7) introducida por la revisión de febrero de 2008 se refiere a «la modificación de las normas de adopción de actos de la Unión Europea en los casos previstos, en lo relativo a la revisión simplificada de los Tratados o a la cooperación judicial civil» en el Tratado de Lisboa. En este caso, el Parlamento -las dos Cámaras conjuntamente- puede oponerse a cualquier eventual modificación de las referidas normas mediante «una moción, adoptada en términos idénticos por la Asamblea Nacional y el Senado.» Cabe reseñar que en este caso, a diferencia de lo que ocurría en el anterior (art. 88-6), no es cada una de las Cámaras sino el Parlamento integrado por ambas conjuntamente la instancia que interviene; lo que ha suscitado alguna objeción doctrinal por la equiparación que ello supone entre ambas Cámaras, no acorde con el esquema bicameral francés que otorga la primacía a la Asamblea Nacional. Hay que hacer notar, sin embargo, como observa Sánchez Navarro, ${ }^{77}$ que dada la cuestión de que se trata -revisión de los Tratados- parece lógico que sea el Parlamento (ambas Cámaras) y no sólo una de ellas quien esté facultado para plantear la correspondiente moción.

77 A.J. SANCHEZ NAVARRO: «Actualidad política y constitucional francesa (20072008)», Teoría y Realidad Constitucional (TRC), n 22, 2008, pag. 458. 


\section{VIII. ÚLTIMAS MODIFICACIONES INTRODUCIDAS EN EL MARCO DE LA AMPLIA REVISIÓN CONSTITUCIONAL SOBRE LA MODERNIZACIÓN DE LAS INSTITUCIONES}

1. Pocos meses después de la reescritura, en los términos señalados, del Tit. XV de la Constitución relativo a la Unión Europea, va a tener lugar una nueva revisión constitucional ${ }^{78}$ que, aunque en esta ocasión no tiene como finalidad la regulación de las relaciones con la UE, sin embargo va a acabar afectando a algunas de las disposiciones del referido Título constitucional. En unos casos, las modificaciones introducidas no suponen (como se verá a continuación) cambios de contenido, limitándose a aspectos formales, de redacción o de actualización del texto (aunque cabe preguntarse, en este caso, porqué no se efectuaron esas modificaciones cinco meses antes (en febrero 2008) cuando se realizó la anterior revisión); pero hay un punto que merece especial atención, como es el de la denominada "cláusula turca» (art. 88-5) que es objeto de cambios que van más allá de los aspectos meramente formales o de redacción, introduciendo elementos nuevos de marcada significación política.

Esta nueva (la séptima), y última (por el momento), revisión constitucional relativa a la UE, debe ser encuadrada en el marco, más amplio, de la gran revisión constitucional realizada recientemente (julio 2008) con el fin de actualizar el sistema institucional de la V República, en su conjunto. ${ }^{79}$ Se trata, sin duda, de la revisión constitucional más amplia de todas las realizadas hasta el presente y que presenta, como característica distintiva, el carácter global con que ha sido planteada, a diferencia de las numerosas, y parciales, revisiones anteriores. Es en este marco general, caracterizado por la reordenación institucional de la $\mathrm{V}$ República, en el que hay que situar las modificaciones puntuales en el ámbito específico relativo a la Unión Europea introducidas por el legislador constitucional francés en julio de 2008.

No es posible en estas líneas dedicar la atención debida a esta última revisión constitucional de julio de 2008 ya que, debido a su amplitud, necesariamente ha de ser objeto de un estudio dedicado específicamente al tema. ${ }^{80}$ Baste reseñar

${ }^{78}$ Ley constitucional no 2008-724 de 23 julio 2008, de modernización de las instituciones de la V República (J.O. de 24 julio 2008)

79 Vid. los números monográficos dedicados a este tema, coincidiendo con el cincuenta aniversario de la Constitución, en Revue Politique et Parlamentaire, no 1048, 2008; Pouvoirs, no 126 , 2008; Revue Française de Droit Constitutionnel, no 77 y 78, 2009.

${ }^{80}$ La revisión constitucional de julio de 2008 , coincidente en el tiempo con el cincuenta aniversario de la Constitución francesa (Octubre 1958), supone la culminación de la evolución 
que la extensa ley constitucional (47 artículos que afectan a aproximadamente otras tantas disposiciones constitucionales) que plasma la última revisión proyecta sus efectos sobre más de la mitad del texto constitucional, con especial incidencia en las cuestiones institucionales, que son las que en esta ocasión constituyen el eje de la revisión. Aunque, como en otras ocasiones, el legislador constitucional ha aprovechado la oportunidad que le proporcionaba esta revisión de carácter general para introducir nuevas modificaciones relativas a la UE, tan solo cinco meses después (febrero- julio 2008) de reescribir el Tit. XV de la Constitución.

Centrándonos en las modificaciones introducidas en las disposiciones del reescrito Tit. XV, relativo a la Unión Europea, éstas pueden ser agrupadas en tres grupos diferenciados, en función del alcance de los cambios en el contenido constitucional de la norma modificada. Así, en un primer grupo nos encontramos con aquellas modificaciones que afectan principalmente a la redacción del texto, sin que comporten cambios apreciables en cuanto al contenido constitucional; tal es el caso de la supresión de las referencias a la Comunidad europea una vez entre en vigor el Tratado de Lisboa o la supresión, por redundante, de la alusión a «los preceptos sobre materias de reserva de ley» en los proyectos de actos legislativos europeos que el Gobierno (francés) debe someter a las cámaras parlamentarias desde el momento de su transmisión al Consejo de la Unión Europea (art. 88-4). Así mismo, se puntualiza que la posibilidad de que las Cámaras adopten resoluciones europeas se extiende a «cualquier documento emanado de una institución de la Unión Europea» (art. 88-4)

Si bien estas modificaciones del texto constitucional no implican, como se acaba de decir, ningún cambio de relieve en cuanto al contenido constitucional, sí cabe preguntarse, sin embargo, porqué no se realizaron cinco meses antes, aprovechando la reescritura del Tit. XV de la Constitución en la anterior revisión (febrero 2008). No parece una técnica constitucional muy adecuada la permanente y continua modificación del texto constitucional, que en principio debe tener una estabilidad mayor que cualquier otra norma, sin que se hayan producido cambios de la suficiente envergadura (lo que no ha ocurrido entre febrero y julio de 2008) que justifiquen la necesidad de remodificar de nuevo, en tan corto espacio de tiempo, el texto constitucional.

En un segundo grupo pueden incluirse aquellos cambios que tienen relación con la reordenación institucional efectuada en el marco de la gran revisión constitucional de julio 2008. A este respecto, es preciso mencionar la novedad

institucional de la V República. A este tema hemos dedicado un estudio que será publicado próximamente. 
que supone la previsión constitucional de instituir una comisión, en el seno de cada Cámara, dedicada específicamente a los asuntos europeos (art. 88-4, nuevo par. $3^{\circ}$ ). Se trata de la única comisión parlamentaria que es objeto de una referencia expresa e individualizada en el texto constitucional; a las demás comisiones parlamentarias -permanentes o especialmente designadas para un tema- se hace una alusión genérica, en el marco de la disposición relativa a la tramitación parlamentaria de los proyectos y proposiciones de ley (art. 43, ligeramente modificado en esta revisión constitucional para aumentar, de seis a ocho, el límite máximo de comisiones parlamentarias permanentes en cada Cámara.).

Igualmente, otra de las modificaciones introducidas en relación con la reordenación institucional derivada de la revisión constitucional que comentamos, hace referencia a la previsión (ya contemplada desde la anterior revisión; febrero 2008), de que las Cámaras parlamentarias puedan plantear un recurso ante el Tribunal de Justicia de la UE contra un acto legislativo europeo por vulneración del principio de subsidiariedad. Ahora, en esta revisión (julio 2008), se puntualiza que la iniciativa para ello puede ser adoptada, y el recurso ha de seguir su tramitación, siempre que tenga el respaldo de sesenta diputados o sesenta senadores $;{ }^{81}$ de esta forma, se permite a las minorías jugar un papel más activo que no podrían jugar de exigirse la mayoría de los miembros de las Cámaras.

Un comentario específico merecen las modificaciones que esta revisión constitucional introduce en la denominada "cláusula turca». Como ya se ha indicado anteriormente (ver supra) se trata de una disposición constitucional (art. 88-5) que, sin mencionar expresamente a Turquía, está destinada a este país, exigiéndose un referéndum, que preceptivamente deberá convocar el Presidente de la República, ante la eventual incorporación de un nuevo Estado miembro a la Unión Europea (o a las Comunidades europeas, de acuerdo con la redacción inicial de esta disposición constitucional). Fue introducida, por primera vez, en la revisión constitucional de marzo de 2005, con motivo del proyecto de Tratado constitucional de la UE, y retocada posteriormente (eliminando la referencia a las Comunidades europeas cuando entre en vigor el Tratado de Lisboa) en el marco de la reescritura del Tit. XV realizada en la anterior revisión, de febrero de 2008. Cinco meses después (julio 2008) vuelve a ser objeto de una nueva modificación que será aprobada tras una fuerte polémica sobre el tema.

${ }^{81}$ El mismo número de diputados y senadores requerido para plantear ante el Consejo Consittucional la constitucionalidad de una ley, de acuerdo con la redacción del art. 61, par. $2^{\circ}$, resultante de la ley constitucional no 74-904 de 29 de octubre de 1974. Y también para plantear ante el mismo órgano la constitucionalidad de un compromiso internacional, de acuerdo con la redacción del art. 54 resultante de la ley constitucional no 92-554 de 25 de junio de 1992. 
A pesar de ser una cuestión colateral en relación con la reforma y modernización institucional, que constituía el eje central de la última revisión (julio 2008), se ha convertido, sin embargo, en uno de los temas que mayor polémica y controversia ha suscitado, tanto en la opinión pública en general como en los círculos políticos franceses en particular. Los constantes comentarios en los medios de comunicación al respecto, así como las declaraciones de las figuras políticas más relevantes, en el curso del debate sobre la revisión constitucional, son una muestra ilustrativa del interés que este tema despierta en el país vecino. ${ }^{82} \mathrm{In}$ terés que sigue manteniéndose tras la realización de la última revisión constitucional, como se ha puesto de manifiesto en las recientes elecciones europeas, en las que este tema, a diferencia de otros países, ha seguido dando lugar a una fuerte polémica entre las formaciones políticas que concurrían a las elecciones. ${ }^{83}$

Los cambios introducidos en la controvertida "cláusula turca» (art. 88-5) abren, en realidad, una vía alternativa a la contemplada, con carácter general, para el supuesto de una eventual incorporación a la UE de un nuevo Estado (que requería, como ya sabemos, la realización de un referéndum en Francia, convocado por el Presidente de la República). De acuerdo con la nueva redacción del art. 88-5, tras la adición de un nuevo párrafo (segundo), el preceptivo y obligatorio referéndum puede ser obviado siempre que las Cámaras parlamentarias adopten una moción al respecto, en términos idénticos en cada Cámara, por una mayoría cualificada de tres quintos; en cuyo caso, «el Parlamento puede autorizar la adopción del proyecto de ley [sobre la ratificación del Tratado relativo a la adhesión de un Estado a la UE] de acuerdo con el procedimiento previsto en el tercer párrafo del art, 89»; que es la disposición constitucional que prevé la posibilidad de realizar una revisión constitucional sin necesidad de hacer un referéndum, requiriéndose en este caso una mayoría cualificada de tres quintos de los votos emitidos en el Parlamento (integrado por ambas Cámaras),

${ }^{82}$ Mi estancia en Francia durante los días (junio-julio 2008) en los que tenía lugar el debate parlamentario sobre la revisión constitucional así como la lectura de la prensa diaria y de las revistas de actualidad política, me permitieron conocer directamente el peso que la "cuestión turca» tiene en el debate político francés (lo que, por otra parte, no deja de sorprender a un visitante extranjero). [Aprovecho la ocasión para agradecer al Colegio de España, en París (y en particular a su director, Javier de Lucas), la acogida en ese centro ya que gracias, en buena medida, a la estancia en él ha sido posible la realización de este trabajo, así como también de otro más amplio sobre la reforma institucional en la revisión de julio de 2008, que será publicado próximamente].

${ }^{83}$ Una vez redactado este trabajo, la campaña electoral de las recientes elecciones al Parlamento europeo (junio 2009) suministra datos que permiten constatar que todas las formaciones políticas francesas formulan propuestas, en sus programas electorales, relativas a la eventual incorporación de Turquía a la Unión Europea 
reunido en Congreso. Así pues, la modificación introducida (en el art. 88-5) supone extender el procedimiento previsto para la revisión constitucional (art. 89, tercer párrafo) a la eventual admisión de la incorporación de un nuevo miembro a la UE.

En el fondo, de lo que se trata con esta nueva reescritura de la «cláusula turca» (art. 88-5) es de proporcionar cobertura constitucional a una doble vía para la admisión de nuevos miembros en la UE.; o, para ser más precisos, de abrir la posibilidad de aplicar vías distintas a Turquía, por una parte, y a los demás países europeos (balcánicos sobre todo) que pidan su ingreso en la UE. A estos últimos se les eximiría del referéndum que, en principio, se preveía con carácter general para todos los países que deseasen incorporarse ala UE, ya que no sería difícil conseguir la mayoría requerida de tres quintos en cada Cámara para evitarlo. Turquía, por el contrario, dada la actual composición de las Cámaras, no podría eludir el referéndum; con escasísimas, por no decir nulas, posibilidades de conseguir en él un resultado favorable a su integración en la Unión Europea. ${ }^{84}$

Con una técnica legislativa a nuestro entender muy discutible ${ }^{85}$ (por la falta de claridad y la confusión a la que puede inducir, como ya se ha reiterado anteriormente, ver supra) el legislador constitucional francés de julio 2008, dedica otra disposición (art. 47) de la ley constitucional de revisión a introducir nuevas modificaciones adicionales en la ya modificada, en los términos indicados, «cláusula turca» (art. 88-5); añadiendo ahora que este artículo «no será aplicable a las adhesiones siguientes a una conferencia intergubernamental cuya convocatoria haya sido decidida por el Consejo europeo con anterioridad al 1 de Julio 2004». No deja de llamar la atención que el legislador constitucional francés, en julio de 2008, se retrotraiga a las convocatorias realizadas por el Consejo europeo, en julio de 2004, para determinar las condiciones de aplicabilidad del reescrito art. 88-5 cuatro años después, tras la última revisión constitucional. Ello tiene explicación, sin embargo, si se tiene en cuenta que con la redacción

${ }^{84}$ Si bien minoritarias, no faltan quienes mantienen posiciones favorables a la incorporación de Turquía a la Unión Europea. Cabe mencionar, en este sentido, por lo reciente de sus manifestaciones, en la campaña electoral europea, y por la destacada personalidad de sus autores, Pierre MOSCOVICI, ex ministro para asuntos europeos en el gobierno de L Jospin (1997-2002), y Pierre WEIL, fundador y expresidente del prestigioso grupo Sofres: «Oui, nous avons besoin de la Tirquie en Europe;", Le Monde, 1 julio 2009.

${ }^{85}$ No somos los únicos que opinamos así. Vid. también la posición crítica que sobre la revisión constitucional en relación con la integración europea mantiene Laetitia GUILLOUD: «Revisión constitutionnelle et intégration européenne, l'insoutenable légèreté de la Constitution», Revue de Droit Public et de la Science Politique, no 2, 2009, pag. 397 y ss. 
empleada Croacia (así como Rumania y Bulgaria, ya integradas en la UE) queda exenta de la aplicación del art. 88-5, mientras que tiene plena aplicación, por el contrario, en el caso de Turquía, sin que siquiera haya necesidad de mencionarla expresamente.

\section{Title}

The European Union and the process of constitutional reform in France (1992-2008)

\section{Summary \\ I. THE EUROPEAN INTEGRATION AND ITS CONSTITU- TIONAL INCIDENCE IN STATES MEMBERS OF THE EU. IN PARTICULAR, IN FRANCE. II. TREATY OF MAASTRICHT AND THE RECEIPT OF THE EU IN THE FRENCH CONSTI- TUTION. III. THE SCHENGEN AGREEMENTS AND RIGHT OF ASYLUM IN THE NEW FRAMEWORK OF THE EU. IV. TREATY OF AMSTERDAM, THE FREE MOVEMENT OF PER- SONS AND CONTROL OF THE PARLIAMENTARY CAME- RAS. V. THE EUROPEAN ARREST ORDER AND JUDICIAL COOPERATION IN THE EU. VI. THE FRUSTRATED DRAFT CONSTITUTIONAL TREATY OF THE EU. THE «TURKISH CLAUSE». VII. TREATY OF LISBON AND REWRITE THE TIT. XV RELATIVE TO TE EU. THE STRENGTHENING OF PAR- LIAMENTARY CONTROL. VIII. LATEST MODIFICATIONS INTRODUCED IN THE FRAMEWORK OF THE BROAD CONSTITUTIONAL REVISION ON THE INSTITUTIONS MODERNIZATION.}

\section{Resumen:}

Se estudia en este trabajo el intenso proceso de revisión constitucional que ha tenido lugar en Francia desde los comienzos de la pasada década (1992) como consecuencia del desarrollo del proceso de integración europea en este último periodo. Se examinan, en particular, las siete revisiones constitucionales que, entre 1992 y 2008, se han sucedido en el país vecino con el fin de hacer compatible la Constitución francesa con el nuevo marco supraestatal europeo que vienen definiendo los sucesivos Tratados de la Unión Europea. 


\title{
Palabras clave
}

Unión Europea, Constitución francesa, revisión constitucional

Key words:

European Union, French Constitution, Constitutional revision.

\begin{abstract}
This work deals with the intense process of constitutional revision that has taken place in France since the beginning of the previous decade (1992) as a result of the development of the european integration process from the onwards. Paticulary, the work is focused on the seven constitutional revisions that, between 1992 and 2008, followed one another in the neighbouring country with the aim of making the French Constitution compatible with the suprastatal european frame defined by the successive treaties of the European Union.
\end{abstract}

